\title{
Learning Progressions in Science: An Evidence-Based Approach to Reform
}

Thomas B. Corcoran

University of Pennsylvania, tomc@gse.upenn.edu

Frederic A. Mosher

Aaron Rogat

Follow this and additional works at: https://repository.upenn.edu/cpre_researchreports

Part of the Curriculum and Instruction Commons, Educational Administration and Supervision Commons, Educational Assessment, Evaluation, and Research Commons, Educational Methods Commons, and the Education Policy Commons

\section{Recommended Citation}

Corcoran, Thomas B.; Mosher, Frederic A.; and Rogat, Aaron. (2009). Learning Progressions in Science: An Evidence-Based Approach to Reform. CPRE Research Reports.

Retrieved from https://repository.upenn.edu/cpre_researchreports/53

View on the CPRE website.

This paper is posted at ScholarlyCommons. https://repository.upenn.edu/cpre_researchreports/53

For more information, please contact repository@pobox.upenn.edu. 


\title{
Learning Progressions in Science: An Evidence-Based Approach to Reform
}

\author{
Abstract \\ American education policy seems poised to escalate and shift its two decade long commitment to \\ standards and outcome-based reform. That commitment has involved a set of "grand bargains", in which \\ the federal government provides Title I (The "No Child Left Behind Act" or NCLB) disadvantaged education \\ funds in return for the states' agreeing to set ambitious content standards, and define performance or \\ "proficiency" standards associated with them that all students in the states' schools will be expected to \\ meet by the 2013/2014 school year. The disadvantaged children targeted by Title I are expected to meet \\ the same standards as all of the rest of the children in each state. In return for agreeing to hold their \\ schools accountable for meeting these expectations, the states are left free to set their standards and \\ their related measures of proficiency as they wish, within some broadly defined parameters. And the local \\ school systems and schools in each state, in return for their share of the Title I/NCLB money are left free, \\ for the most part, to choose their preferred approaches to instruction as long as they agree to be held \\ accountable for ensuring that all their students are making adequate progress towards meeting the \\ state's proficiency goals. So, the general form of each bargain is an agreement to reduce or forgo \\ regulation of inputs in return for a commitment to define, and meet, outcome expectations. \\ But, having agreed to do something they had never before tried to do-to succeed with essentially all \\ students-schools and educators face the problem that they don't know how to meet their side of the \\ bargain. Proponents and observers of reform claim to be shocked that some states are setting their \\ performance standards in ways that minimize or disguise the degree to which their students are likely to \\ fail to meet the hopes of reform. In addition, schools and teachers are resorting to approaches, such as \\ relentless test preparation and focusing on students who are just at the edge of meeting proficiency \\ requirements, that try to meet the letter of the bargains' requirements while leaving the more ambitious \\ spirit of the reforms' hopes well behind, along with all too many children.

\section{Disciplines} \\ Curriculum and Instruction | Educational Administration and Supervision | Educational Assessment, \\ Evaluation, and Research | Educational Methods | Education Policy

\section{Comments} \\ View on the CPRE website.
}




\section{GRE}

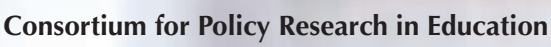

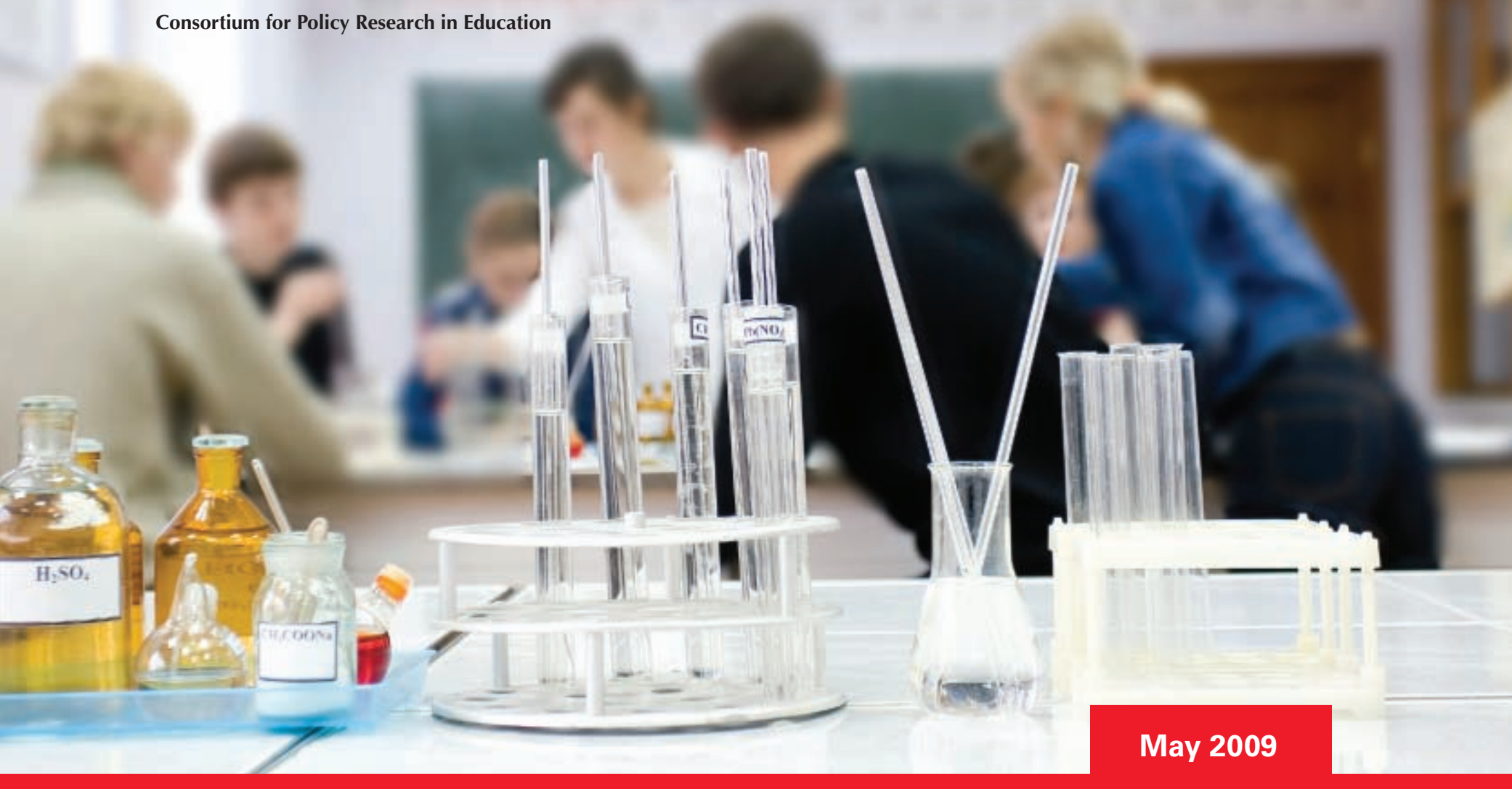

\section{Learning Progressions in Science}

An Evidence-based Approach to Reform

Prepared by

Tom Corcoran Frederic A. Mosher Aaron Rogat

Center on Continuous Instructional Improvement Teachers College-Columbia University 


\section{About the Consortium for Policy Research in Education (CPRE)}

Established in 1985, CPRE unites researchers from seven of the nation's leading research institutions in efforts to improve elementary and secondary education through practical research on policy, finance, school reform, and school governance. CPRE studies alternative approaches to education reform to determine how state and local policies can promote student learning. The Consortium's member institutions are the University of Pennsylvania, Teachers College-Columbia University, Harvard University, Stanford University, the University of Michigan, University of Wisconsin-Madison, and Northwestern University.

In March 2006, CPRE launched the Center on Continuous Instructional Improvement (CCII), a center engaged in research and development on tools, processes, and policies intended to promote the continuous improvement of instructional practice. CCII also aspires to be a forum for sharing, discussing, and strengthening the work of leading researchers, developers and practitioners, both in the United States and across the globe.

To learn more about CPRE and CCII, visit our web sites at www.cpre.org and www.ccii-cpre.org. 


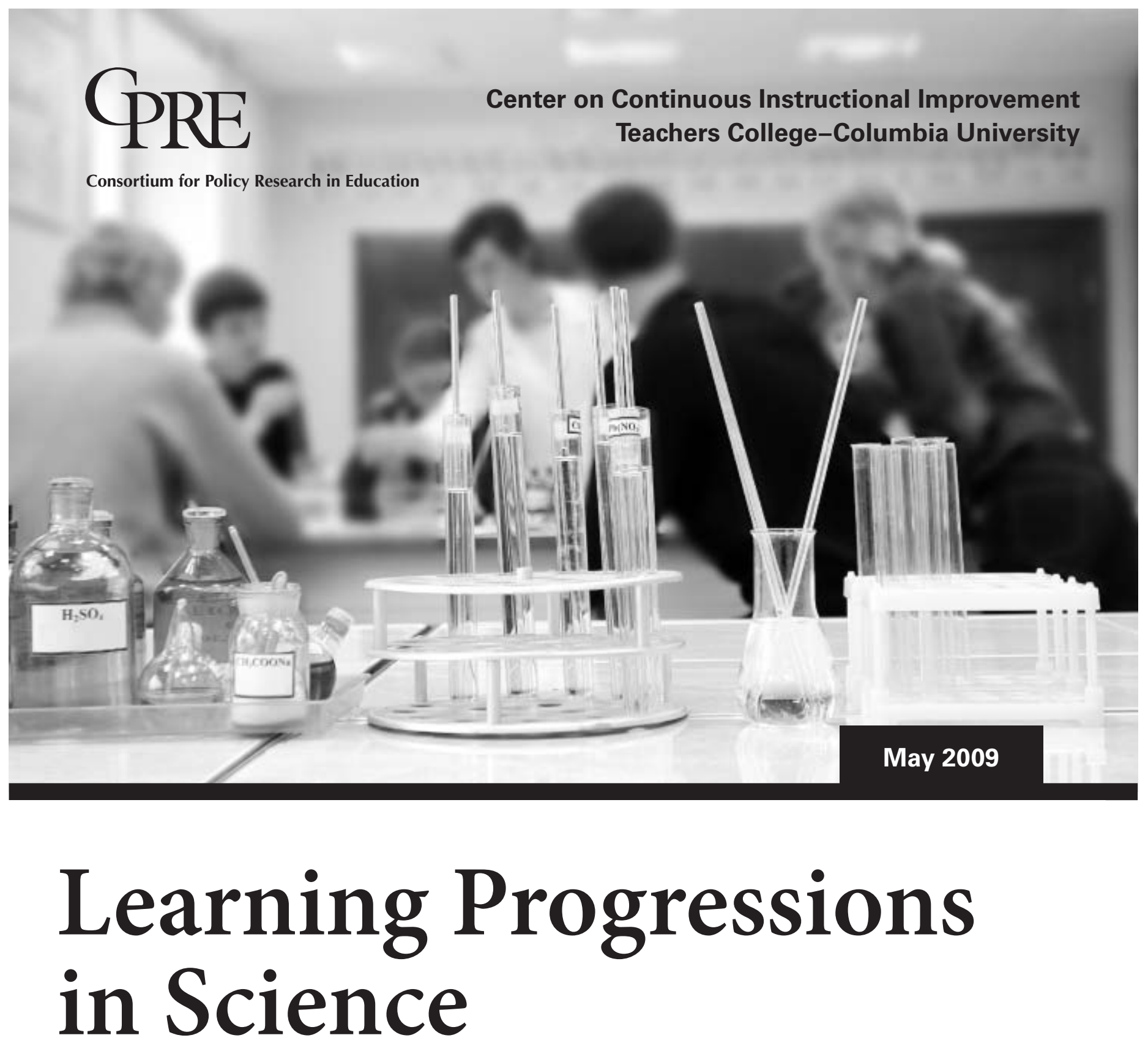

\section{An Evidence-based Approach to Reform}

Prepared by

Tom Corcoran Frederic A. Mosher

Aaron Rogat

CPRE Research Report \# RR-63

All data presented, statements made, and views expressed in this report are the responsibility of the authors and do not necessarily reflect the views of the Consortium for Policy Research in Education, its institutional partners, or the funders of this study-Pearson Education and The Hewlett Foundation. This report has been internally and externally reviewed to meet CPRE's quality assurance standards. 



\section{Table of Contents}

Executive Summary................................. 7

I. Introduction $\ldots \ldots \ldots \ldots \ldots \ldots \ldots \ldots \ldots \ldots \ldots \ldots \ldots \ldots \ldots \ldots \ldots$

Why Are Reforms Needed?. . . . . . . . . . . . . . . . . . . . 12

II. Learning Progressions: New Tools for Improvement . . . . . . . . . 15

III. The Potential Benefits of Learning Progressions $\ldots \ldots \ldots \ldots \ldots \ldots \ldots 17$

Improved Standards and Curriculum $\ldots \ldots \ldots \ldots \ldots \ldots \ldots \ldots \ldots \ldots \ldots \ldots \ldots \ldots \ldots$

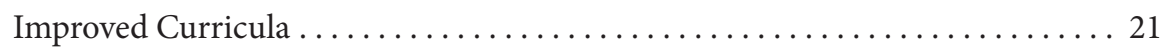

Improved Assessments. . . . . . . . . . . . . . . 22

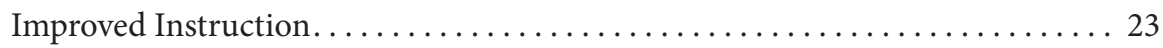

IV. Recent Work on Learning Progressions $\ldots \ldots \ldots \ldots \ldots \ldots \ldots \ldots$

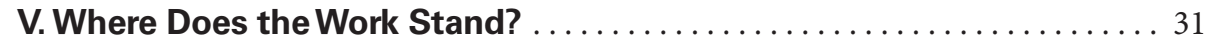

A Close Look at Three Learning Progressions . . . . . . . . . . . . . . 33

Example 1: Buoyancy................................. 34

Example 2: Atomic Molecular Theory.................... 35

Example 3: Tracing Carbon in Ecosystems.................... 37

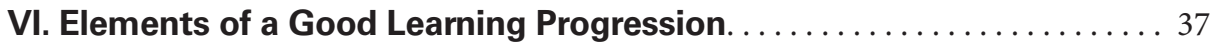

The Panel's Working Definition $\ldots \ldots \ldots \ldots \ldots \ldots \ldots \ldots \ldots \ldots \ldots \ldots \ldots \ldots \ldots \ldots \ldots \ldots$

VII. The Validation of Learning Progressions ................ 41

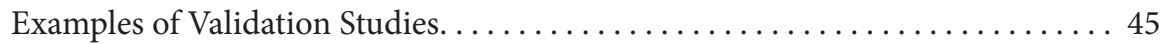

Consequential Validation $\ldots \ldots \ldots \ldots \ldots \ldots \ldots \ldots \ldots \ldots \ldots \ldots \ldots \ldots \ldots \ldots \ldots \ldots$

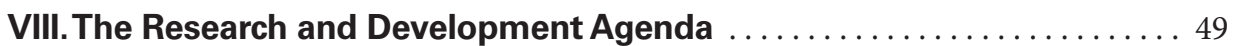

Why Should These Steps be Taken? .................... 52

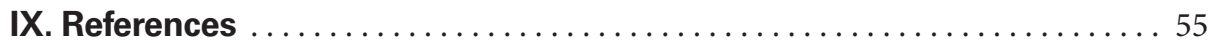

Appendix A. CCII Science Panel Meeting Participants . . . . . . . . . . . . . 59

Appendix B. Table of Learning Progressions in Science Discussed, . . . . . 61 Mentioned, and Identified by Panelists

Appendix C. Examples of Learning Progressions. . . . . . . . . . . . 69 


\section{Author Biographies}

Tom Corcoran is Co-director of the Consortium for Policy Research in Education (CPRE) at Teachers College, Columbia University and principal investigator of the Center on Continuous Instructional Improvement (CCII). Corcoran's research interests include strategies for improving instruction, the use of research findings and clinical expertise to inform instructional policy and practice, the effectiveness of different approaches to professional development, knowledge management systems for schools, and the impact of changes in work environments on the productivity of teachers and students.

Previously, Corcoran served as Policy Advisor for Education for New Jersey Governor Jim Florio, Director of School Improvement for Research for Better Schools, and Director of Evaluation and Chief of Staff of the New Jersey Department of Education. He has served as a consultant to urban school districts and national foundations on improving school effectiveness and equity. He served as a member of the National Research Council's K-8 Science Learning Study and its Steering Committee on Evaluating Options for Common Standards, and has been a visiting professor of education policy at the Woodrow Wilson School of International and Public Affairs at Princeton University since 1999.

Frederic A. (Fritz) Mosher is Senior Research Consultant to CPRE. Mosher is a cognitive/ social psychologist and knowledgeable about the development and use of learning progressions. He has worked with CPRE on the CCII since its inception, helping to design the Center and taking a lead role in the Center's work on learning progressions. Mosher also has extensive knowledge of, and connections with the philanthropic community, reform organizations, and federal agencies. He has been advisor to the Spencer Foundation, a RAND Corporation adjunct staff member, advisor to the Assistant Secretary for Research and Improvement in the U.S. Department of Education, and a consultant to Achieve, Inc. For thirty six years he was a program specialist with varying responsibilities at Carnegie Corporation of New York.

Aaron Rogat is a Senior Scientist at CPRE-Teachers College. Rogat has a background as a practicing scientist (Molecular Cell Biology) as well as six years of experience in science education. He provides technical assistance on the development and implementation of professional development for science teachers. In the past, Rogat has developed a number of standards-based, inquiry-oriented curriculum materials in science and has conducted classroom-based research focused on the implementation of curriculum materials and the student learning resulting from their use. In particular, he has studied student learning in genetics and chemistry. He has also collaborated on the development of a learning progression in genetics. 


\section{Foreword}

A major goal of the Center on Continuous Instructional Improvement (CCII) is to promote the use of research to improve teaching and learning. In pursuit of that goal, CCII is assessing, synthesizing and disseminating findings from research on learning progressions in science, mathematics, and literacy, and promoting and supporting further development of progressions as well as research on their use and effects. ${ }^{1}$ CCII views learning progressions as potentially important, but as yet unproven tools for improving teaching and learning, and recognizes that developing and utilizing this potential poses some challenges.

The purpose of this report is to describe the work that has been done so far on learning progressions in science, examine the challenges to developing usable learning progressions, determine if further investments are warranted, and if so, what investments are needed to realize their promised benefits. The report examines the quality and utility of the work done to date and identifies gaps in the fields that would have to be addressed in order to move the work forward. We hope this assessment of these fields of work will inform the national research and development agenda and be useful to those interested in learning progressions, including researchers, curriculum developers, teacher educators, assessment developers and policymakers.

In order to develop the report, CCII invited experts in science education and cognitive science and formed a panel to review and discuss the state of the current work on learning progressions. The panel met twice in two-day meetings supported by funding from Pearson Education and the Hewlett Foundation. Twenty-one participants including science educators, learning scientists, psychologists, assessment experts, policy researchers, and curriculum developers attended these meetings (a list of the attendees can be found in Appendix A). Many of the panel members have been actively engaged in developing and testing learning progressions in science.

CCII staff Aaron Rogat, Tom Corcoran, and Fritz Mosher from Teachers College, Columbia University organized and planned the meetings in collaboration with the meeting chair, Joseph Krajcik of the University of Michigan. At the meetings, the panelists and CCII staff reviewed a cross-section of the work on science learning progressions; these progressions are listed and briefly described in Appendix B. A number of developers shared their work on learning progressions and the procedures to develop and validate them. This led to rich discussions about the development processes used and the characteristics of usable learning progressions. Participants discussed the common elements in their work and some divergent approaches to the development of learning progressions as well as challenges to developing and validating them.

${ }^{1}$ The term progressions is used throughout the document is short-hand for learning progressions. 
This report has been informed by these discussions and addresses 1) the nature and quality of existing work on learning progressions in science, 2) the essential elements of learning progressions, 3 ) the outstanding issues, challenges and debates about learning progressions in science, and 4) the research and development that must be done to realize their potential as tools for improving teaching and learning. The recommendations are based on our review of transcripts of the discussions at the panel meetings; review of research reports, papers, and funding awards on learning progressions; and extended conversations with many of the participants in the meetings. While drafts of the report were reviewed by the meeting participants as well as external reviewers, and their feedback was enormously helpful, the responsibility for the arguments raised in the report and the recommendations rests with CCII. 


\section{Executive Summary}

American education policy seems poised to escalate and shift its two decade long commitment to standards and outcome-based reform. That commitment has involved a set of "grand bargains", in which the federal government provides Title I (The "No Child Left Behind Act" or NCLB) disadvantaged education funds in return for the states' agreeing to set ambitious content standards, and define performance or "proficiency" standards associated with them that all students in the states' schools will be expected to meet by the 2013/2014 school year. The disadvantaged children targeted by Title I are expected to meet the same standards as all of the rest of the children in each state. In return for agreeing to hold their schools accountable for meeting these expectations, the states are left free to set their standards and their related measures of proficiency as they wish, within some broadly defined parameters. And the local school systems and schools in each state, in return for their share of the Title I/NCLB money are left free, for the most part, to choose their preferred approaches to instruction as long as they agree to be held accountable for ensuring that all their students are making adequate progress towards meeting the state's proficiency goals. So, the general form of each bargain is an agreement to reduce or forgo regulation of inputs in return for a commitment to define, and meet, outcome expectations.

But, having agreed to do something they had never before tried to do-to succeed with essentially all students-schools and educators face the problem that they don't know how to meet their side of the bargain. Proponents and observers of reform claim to be shocked that some states are setting their performance standards in ways that minimize or disguise the degree to which their students are likely to fail to meet the hopes of reform. In addition, schools and teachers are resorting to approaches, such as relentless test preparation and focusing on students who are just at the edge of meeting proficiency requirements, that try to meet the letter of the bargains' requirements while leaving the more ambitious spirit of the reforms' hopes well behind, along with all too many children.

In the face of this, what do reform proponents recommend? Naturally, they recommend shifting to common, or national, content and performance standards, so that states cannot hide their failures, and while they are at it, they recommend that those common standards be raised to more ambitious levels that would match those that seem to be attained by the highest performing of our global competitors, ones that would meet the presumed demands of this new, 21st Century.

At the Center for Continuous Instructional Improvement (CCII) we have an alternative, or perhaps an additional, suggestion to make. We think it is time to reconsider the other side of the bargain and to focus on developing and making available the knowledge, tools, infrastructure and resources that would make it possible for educators and their students to deliver on the promised outcomes. These bargains never were very Faustian. The good stuff of the money and the eased regulation on inputs were never that good, but it now certainly is time to focus on the devilish details. 
We are convinced that it is not possible for the reform goals with respect to "all students" to be met unless instruction in our schools becomes much more adaptive. That is, the norms of practice should shift in the direction in which teachers and other educators take responsibility for continually seeking evidence on whether their students are on track to learning what they need to if they are to reach the goals, along with tracking indicators of what problems they may be having, and then for making pedagogical responses to that evidence designed to keep their students on track, or to get them back on track, moving toward meeting the goals. This, of course, is a description of a formative assessment process in action. We are additionally convinced that teachers will not be able to engage in such processes unless they have in their minds some idea about how students' learning in the subjects they are teaching develops over their time in school, as well as some idea of the ways of responding to evidence of their progress or problems that are likely to be effective. We have been looking for promising ideas about what this metaphor of "on track" (or its obverse- "off track") might mean in terms that could be accessible to and useful for teachers and their students.

One such idea that has attracted growing attention in education reform circles is the concept of "learning progressions." This is a report on the results of our convening a group of experts to explore this concept, what promise it might hold for improving instruction in our schools, and, if it seems promising, what further might be required to make that promise real-all in the specific context of science education.

This, briefly, is what we found: Learning progressions in science are empirically grounded and testable hypotheses about how students' understanding of, and ability to use, core scientific concepts and explanations and related scientific practices grow and become more sophisticated over time, with appropriate instruction (NRC, 2007). These hypotheses describe the pathways students are likely to follow to the mastery of core concepts. They are based on research about how students' learning actually progresses-as opposed to selecting sequences of topics and learning experiences based only on logical analysis of current disciplinary knowledge and on personal experiences in teaching. These hypotheses are then tested empirically to assess how valid they are (Does the hypothesized sequence describe a path most students actually experience given appropriate instruction?) and ultimately to assess their consequential validity (Does instruction based on the learning progression produce better results for most students?). If this work is pursued vigorously and rigorously, the end result should be a solid body of evidence about what most students are capable of achieving in school and about the particular sequence(s) of learning experiences that would lead to proficiency on the part of most students. However, it is not assumed that there is likely to be one best progression or pathway. The number and nature of productive pathways are treated as empirical questions likely to be influenced by variations in instruction and by future design and experimentation.

With the help of the panel, our review of current work on the development of learning progressions in science (we focused primarily on the American literature in this regard) made it clear that, while there is promising work on progressions in some scientific domains and practices, in most cases that work is at the initial stages of producing evidence on the degree of validity and usefulness of these progressions, and, taken together, they do not yet cover enough of the scientific content and practices that should be taught in American schools for them to be able to bear the full weight of replacing standards as 
we currently understand them. Nevertheless, when coupled with thoughtful efforts to define curriculum frameworks that would try to encompass the best we know about how students learn content and practices and what instructional experiences are likely to promote that learning, it might be possible to lay out a picture of what should be taught that would cover most of the ambitions likely to be framed by new higher, fewer, and clearer standards, and to do it in such a way as to have a much better chance of informing teachers' practice.

Beyond this short run effort, CCII and our panel suggest what would be needed in terms of research and development to produce a more comprehensive set of progressions to serve as the backbone of a much more effective science education system. This would require continuing effort, and funding, to refine and test the progressions that now are under development, including making a concerted effort to demonstrate the effects on instruction and improved student outcomes when teaching and assessment are aligned with well tested progressions - to provide a kind of "existence proof" that further investment in developing progressions would be justified. Funders should work with researchers and educators to identify the core science concepts and practices that still need to be covered by progressions, and provide priority support for a strategic plan of extended research, development, and design to ensure the coverage that the schools will need. There are still fundamental questions about the structure of progressions and the ways in which evidence of students' progress along them can be gathered. In particular, we need better understanding of the ways of understanding and characterizing the relations and interactions among the many progressions that students are traversing during the school years, including, but not limited to, the interaction between progressions in learning content and progressions in acquiring key scientific practices. And the problem of devising assessments that report students' performance validly and reliably referenced to the key levels of understanding and skill identified by the progressions, rather than to students' positions relative to other students, will require fundamental advances in psychometric methods.

If this priority work is supported and carried out successfully, CCII is convinced that the resulting progressions can play a central role in supporting the needed shift toward adaptive instruction as the norm of practice in American schools. We offer here a brief list of the possible benefits:

- They should provide a more understandable basis for setting standards, with tighter and clearer ties to the instruction that would enable students to meet them;

- They would provide reference points for assessments that report in terms of levels of progress (and problems) and signal to teachers where their students are, when they need intervention, and what kinds of intervention or ongoing support they need;

- They would inform the design of curricula that are efficiently aligned with what students need to progress;

- They would provide a more stable conception of the goals and required sequences of instruction as a basis for designing both pre- and in-service teacher education; and, 
- The empirical evidence on the relationship between students' instructional experiences and the resources made available to them, and the rates at which they move along the progressions, gathered during their development and ongoing validation, can form the basis for a fairer set of expectations for what students and teachers should be able to accomplish, and thus a fairer basis for designing accountability systems and requirements. 


\section{Introduction}

A broad consensus has emerged in recent years among policymakers, educators, researchers, and the business community about the need for the nation to take urgent action to improve teaching and learning in science in our public schools. Certainly the performance of U.S. students on national and international assessments of K-12 science and mathematics education has been disappointing, and more disturbing are the large gaps in performance associated with family income and race (Gonzales et al., 2008; National Center for Education Statistics, 2006; OECD, 2007). And it is clear that the U.S. needs to raise the level of public literacy in science in order to deal with the challenges of the next century (Salzman \& Lowell, 2008). Explanations for our mediocre performance in science learning as a nation vary, but many critics focus on the quality of our state standards and complain that the curricula in use are a mile wide and an inch deep (Schmidt et al., 2002). Many contend the states should adopt common standards, and argue this should happen immediately. Others believe the solution lies in improving the quality of teachers and teaching, and want the government to offer incentives to hire better teachers. While opinions about what should be done vary, almost all agree that urgent action is needed.

This report is a plea for a more reasoned, deliberate approach, one that employs scientific principles and which engineers solutions that can be tested and refined until they work. We agree actions must be taken, but endorse actions to devise and test solutions rather than embracing popular but unproven ones. We believe we must use what we know to improve teaching and learning in science, and that we must recognize that we do not know all that we need to know. The action that is needed is the development and implementation of a national research and development program to fill in the gaps in our knowledge, and develop the tools needed by curriculum developers, test-makers, and teachers to translate what we do know into practice. This report is about one class of those tools, called learning progressions, and the role they could play in addressing the problems we face in science education, and in other knowledge domains as well. This report explains what learning progressions are and why they are important, and describes the current state of their development, and what must be done to fulfill their potential.

But we must begin our story at the beginning. Why should we be so concerned about the state of science education? Is it not sufficient that we produce enough scientists, doctors, and technicians to fill the jobs available in our nation's universities, businesses, hospitals, and laboratories? Does everyone need to understand science? The answer to the first question is a strong no; it is not sufficient. And the answer to the second one is a qualified yes. In order for our nation's democratic institutions to function effectively in the 21 st century and for our leaders to deal with complex decisions affecting climate change, the environment, public health, and other issues requiring scientific understanding, the vast majority of our citizens must be scientifically literate and capable of understanding scientific reasoning. Clearly we need to prepare adequate numbers of students to become 
scientists to maintain our competitive position in the world economy and to retain our leadership in science, technology, and innovation, but this will not be enough. In this century, it is not just elites who must understand science; full participation in our democracy requires that all citizens be scientifically literate. Achieving our national aspirations requires us to strengthen our science education programs and make science for all a reality rather than a slogan.

Of course this raises two additional questions - what does it mean to be scientifically literate? And, how can this goal be achieved? The current state standards reflect our first try at answering these questions, but the answers have proved inadequate to the task. Our state standards are not providing us with clarity about what is meant by scientific literacy nor are they providing teachers with the guidance they need to provide effective instruction in science.

\section{Why are Reforms Needed?}

Even the most cursory examination of our science standards reveals that there are simply too many of them covering too many disconnected topics at each level, and that they often lack careful vertical articulation. Our high-stakes state assessments do not focus on central concepts and practices in science; rather they rely on simple multiple-choice questions that do not adequately address what we want our students to know and to be able to do. These standards and assessments have led to the use of curricula that are thin and attempt to cover too much in each grade, and this in turn has encouraged instruction that focuses on coverage of topics rather than providing the careful scaffolding required for students to develop integrated and sophisticated understanding of science content. Our students are not spending sufficient time engaged in complex cognitive tasks such as inquiry, argumentation, and explanation and therefore it should be no surprise that many of them do not develop the critical thinking skills we hope they will attain (Kuhn, 2005; NRC, 2007). For many, science class is a thin gruel of badly organized textbooks, worksheets, and memorization of science "facts", and, in part this is because that is what is being demanded by the state standards and high-stakes assessments.

In spite of the rhetoric used by our leaders about the need for rigorous standards and focusing on inquiry, our standards, curricula and assessments fall far short of our national aspirations to provide scientific literacy for all students. These endemic problems with the science standards, curriculum, and assessments are exacerbated by inadequate teacher preparation and certification requirements for science teachers that fail to develop or require the understanding of content, students' learning in science, and the pedagogical approaches that teachers need to support science learning.

Our state and local education systems face major problems in teaching science, and many students fail to acquire even basic proficiency by the time they leave high school. To address these issues, we must decide what is most important to learn, and then develop more parsimonious standards and better articulated curricula that reflect what we know about how children learn science and how their mastery develops over time. The first step toward solving our problems is identifying our learning goals and setting appropriate and effective sequences of learning targets across the grades. We must reach agreement on the essential science concepts and skills that should be taught in schools, in what order they should be taught, and how they should be connected, and we must base these decisions on evidence, not opinion, and re-visit them as new evidence accumulates. 
There is broad agreement among science educators that we should focus on core concepts in science, particularly those that are generative of broader understanding across the scientific disciplines (NRC, 2007). But which concepts, and how are they connected, and when should they be taught? Our education systems and our schools need answers to these questions. They are in desperate need of guidance about how to design better standards, curricula, assessments, and teacher preparation programs. But to address these issues effectively, we must examine the evidence we have about how children learn science, collect more evidence where it is needed, and then design and test curriculum, assessments, and instructional programs based on this knowledge. This requires a shift from consensual models of decision-making that rely on reconciling or accommodating the divergent opinions of stakeholders to evidence-driven models that rely on careful design and testing of hypotheses about curriculum. And it requires the development of new tools such as learning progressions that bridge research and practice, and provide guidance for curriculum developers and teachers. This is the work to be done if our school systems are to improve their policies, supports and programs, and make sustainable progress toward the goal of universal scientific literacy. Only if we behave like scientists and adopt scientific practices to inform our educational policies, are our students likely to be able to make significant achievement gains in science-and in other domains of knowledge as well. We believe learning progressions hold great promise, and might be a useful first step in the effort to change how we think about and conduct improvement in education. 


\section{Learning Progressions: New Tools for Improvement}

Learning progressions in science are empirically-grounded and testable hypotheses about how students' understanding of, and ability to use, core scientific concepts and explanations and related scientific practices grow and become more sophisticated over time, with appropriate instruction (NRC, 2007). These hypotheses describe the pathways students are likely to follow to the mastery of core concepts. They are based on research about how students' learning actually progresses-as opposed to selecting sequences of topics and learning experiences based only on logical analysis of current disciplinary knowledge and on personal experiences in teaching. These hypotheses are then tested empirically to ensure their construct validity (Does the hypothesized sequence describe a path most students actually experience given appropriate instruction?) and ultimately to assess their consequential validity (Does instruction based on the learning progression produce better results for most students?). If this work is pursued vigorously and rigorously, the end result should be a solid body of evidence about what most students are capable of achieving in school and about the particular sequence(s) of learning experiences that would lead to proficiency on the part of most students. However, it is not assumed that there is likely to be one best progression or pathway. The number and nature of productive pathways are treated as empirical questions likely to be influenced by variations in instruction and by future design and experimentation.

So what does a learning progression look like? Later we will take a detailed look at some learning progressions, but for the moment, we offer the reader a general description that builds on the one used by Smith and colleagues (2006), and subsequently by the National Research Council (NRC) K-8 Science Committee in their report, Taking Science to School (NRC, 2007). According to those experienced with their development, learning progressions have five essential components:

1) Learning targets or clear end points that are defined by societal aspirations and analysis of the central concepts and themes in a discipline;

2) Progress variables that identify the critical dimensions of understanding and skill that are being developed over time;

3) Levels of achievement or stages of progress that define significant intermediate steps in conceptual/skill development that most children might be expected to pass through on the path to attaining the desired proficiency;

4) Learning performances which are the operational definitions of what children's understanding and skills would look like at each of these stages of progress, and which provide the specifications for the development of assessments and activities which would locate where students are in their progress; and,

5) Assessments that measure student understanding of the key concepts or practices and can track their developmental progress over time. 
While all members of our Science panel agreed these were essential features of learning progressions, some argued that other features-such as specifying the kinds of instruction and professional development necessary to support the progression-were also essential. While there was no consensus that such features are essential to beginning to define a learning progression, we believe this kind of specification is ultimately necessary to validate them and make them useful. To interpret and use a learning progression, you need to consider the kinds of instruction that the students whose performances were studied had received. There is an interaction between students' development and the kinds of instruction they receive, and the developmental pathways described by a learning progression that can only be used with confidence with students who are receiving instruction similar to that received by the students who were studied to build the progression. To make this point in a different way, the character of the instruction provided can affect the developmental pathway that most children follow. If a learning progression is based on evidence drawn from students who are all receiving instruction of a particular type, then it maybe less generalizable than one based on evidence drawn from studies of children receiving different forms of instruction.

How do these tools differ from other approaches to defining the vertical structure of the public school curriculum such as scope and sequence documents or curriculum frameworks? And why would learning progressions be any more useful for curriculum developers and teachers? Two fundamental differences between learning progressions and these other approaches have to do with how the tools are developed and how they are legitimated. Learning progressions are often initially based on "systematic" examinations of the relevant theory and research about how students learn a particular concept or topic. What do we know about the typical student's entering understandings, misunderstandings and misperceptions? What do we know about the struggles students have with a particular concept? What have we learned about the steps students typically go through? Theory and research findings should guide the development of the hypothesis rather than conventional wisdom or consensus processes. So the first difference is that learning progressions rest on empirical evidence. Learning progressions also differ from other approaches to defining the most appropriate sequence of topics to be studied in how they are legitimated. Scope and sequence documents and curriculum frameworks are legitimated by the authority of experts, professional bodies, and government agencies. Learning progressions are legitimated by evidence gathered through testing, and they can be falsified. They should be tested in the field to see if in fact, most students do follow the predicted pathways when they receive the appropriate instruction and they should be altered and refined based on this evidence. Studies also can be conducted to see if students receiving instruction based on the progressions are more likely to master the target concepts than is the case with students experiencing conventional instruction. Learning progressions provide a solid foundation for developing curriculum and assessments because they are empirically grounded, and they provide a basis for an iterative process of research and development that would improve curriculum and assessment over time. 


\section{The Potential Benefits of Learning Progressions}

Science education researchers, learning scientists, assessment developers, teacher educators, and curriculum developers are interested in the development of learning progressions, and many believe that learning progressions can lead to development of more focused standards, better designed curricula, better assessments, and ultimately more effective instruction and improved student learning of science. They believe that standards and curricula based on learning progressions would be more parsimonious and better aligned vertically because learning progressions would provide clear pathways for development over time of more sophisticated understanding of the core concepts and practices in science.

\section{Improved Standards and Curriculum}

Can learning progressions help us develop new standards that would be more usable and more realistic? Let's first consider how learning progressions and standards differ.

Standards define common content and performance expectations for all students in particular grades or age groups. They are derived from analysis of the structure of the core school disciplines and from efforts to reach consensus about societal goals. The content expectations tend to be aspirational, and the expected performance levels tend to be a negotiated balance between the desire to be rigorous and challenging and the need to be realistic in terms of likely failure rates on the assessments used to measure performance. In contrast, learning progressions represent hypotheses about how students' understanding actually develops given particular instructional experiences, and they can be tested and validated against further empirical observations of the order and rate in which students' understanding and skill do in fact develop given similar instruction. They also can be modified by evidence on what happens when instruction varies. Instead of making assumptions about what should happen, they focus on what does happen, given variation among students and their instructional opportunities.

While the state standards required by No Child Left Behind (NCLB) assume that all students should cover the same content in roughly the same time periods, and meet or exceed the same proficiency expectations at roughly the same time, learning progressions are open to the finding that students' rates of progress along the hypothesized pathways can vary. In this sense, learning progressions are consistent with the original conception of standards-based reform (Smith \& O'Day, 1991) which held that the same levels of proficiency should be set for all students, but that the time and resources needed for them to attain those levels would likely vary. Current NCLB policy holds that by 2014 essentially all students should be expected at least to reach proficiency levels at the same times, grade by grade. 
Standards tend to assume that the ultimate performance targets can be broken down logically-deductively-into chunks of earlier and later knowledge and skill that students should master in order and which then will add up to achievement of the desired proficiency. In contrast, learning progressions are based on empirical studies of how student thinking about a concept and/or mastery of a practice actually develops, with specified instruction. The levels of achievement in a progression represent the levels of development that student thinking typically goes through on the path to the desired understanding and skill. In progressions the earlier levels may reflect mistaken or imperfect understandings of the target concepts that have to be revised or abandoned before the student can move on, rather than, as standards seem often to conceive of them, correct but incomplete understandings that simply have to be supplemented to reach full understanding. For example, for a younger child "having weight" means "feels heavy-affects me by pushing/pulling on my hand." Later in a progression, students will come to understand that having weight (or by then, perhaps, "mass") means having some amount of matter that pushes on things, or resists being pushed, whether or not it is detectable "by me" (Wiser, et al., 2009). The student's concept of weight undergoes a reconceptualization rather than a simple additive modification (and that shift will be more meaningful to the student if it is mediated and motivated by concrete experiences with observation and measurement).

At this point in the development of thinking about progressions the language used to describe the levels of achievement or stages of progress that constitute steps in a progression is not as precise as we might hope it will become, particularly when we are trying to talk about levels as a general feature of progressions rather than about the specific evidence found for the levels in a particular progression. But the hope is that these milestones would represent something more than just getting right answers to a few more test questions. This hope stems from a structural view of cognitive development which suggests that the development of student thinking may not be purely incremental but may proceed as a series of increasingly complex schemes for organizing understanding of the world which may be rather stable for periods of time, but which eventually are modified or even broken down and rebuilt to take account of new evidence and new perceptions (including, of course, new inputs from instruction). The developers of learning progressions try to identify a limited set of these relatively more stable, even if still temporary, consolidations of students' thinking that most students are likely to experience in roughly the same order, and they seek to characterize the other, perhaps more diverse or less ordered, sets of experiences, perceptions, and partial understandings that underlie and are incorporated into these consolidations, as well as those that eventually lead to re-consolidations at later levels.

The proponents of learning progressions clearly are focused on teaching and learningthey assume that getting to the overall goals of schooling involves a journey, and they are concerned with providing maps that would enable teachers and students to tell where students are in that journey, not just in order to see whether they have arrived or fallen short, but rather to help them see where to go next or what has been missed. Progressions are aimed at producing a connected view of the development of students' thinking and skills, drawing a picture of the ways in which students place particular facts and concepts into a more general conception of how those facts and concepts are related, so as to support an understanding of how some aspect of their world works, however rudimentary that understanding may be in the earlier stages of their learning. 
Currently most state standards have a somewhat different focus and structure. Most significantly, they tend to be framed in terms of the desired outcomes of learning without specifying much about how those outcomes might come about or what time periods might be required for mastery by students who enter with different levels of understanding and skill-they focus on the products of students' thinking rather on the ways that thinking develops over time. State content standards try to specify what teachers should teach; performance standards specify how much or how well students should learn these things. They provide very little specification about how instruction mediates between the presentation of content and student outcomes. As a result, standards provide little guidance for teachers about what they should do to ensure that students meet or exceed the standards. Also, because the standards are often a negotiated list resulting from the experience, preferences, and influence of adult stakeholders and are seldom rooted in direct evidence of whether most children can learn everything expected within the time and resources schools provide, they often include many more topics at each grade than it is reasonable to think teachers and students can address at anything more than a superficial level. This provides teachers with considerable incentive to favor coverage over depth of treatment.

There is an obvious tension between thinking about the growth of students' learning as developers of learning progressions do and the way that writers of the current standards have been doing. Learning progressions certainly address the order in which students are likely to learn things, but they do not necessarily specify the ages at which particular milestones should, or are likely to, be reached. Under NCLB the state standards define grade-level proficiency standards that essentially all students are expected to reach or exceed in their grade level cohorts by the year 2014. While the empirical data collected from research on learning progressions might provide evidence that most students would reach particular milestones by a given grade, they also may show that students differ widely in their rates of progress even though they may move through the stages of progress in more or less the same order. In fact, the empirical evidence assembled so far indicates that at any given grade the range of the students' positions on any given progression varies widely. One of the main points of focusing on progressions is to provide teachers with a conceptual structure that will inform and support their ability to respond appropriately to evidence of their students' differing stages of progress by adapting their instruction to what each student needs in order to stay on track and make progress toward the ultimate learning goals.

We recognize that the setting of grade-level proficiency standards for all students is designed to avoid "the soft bigotry of low expectations" for traditionally low performing or disadvantaged students and that some will see a danger in an approach that recognizes, and accepts, that students' performance levels are likely in fact to range quite widely at any given time. They may fear that this would lead schools to accept a low expectations kind of tracking for low performing students. We think this danger can be avoided and that in fact progressions can offer a much more realistic and effective way of setting high standards for all students. Far from encouraging holding low expectations for some students, learning progressions, because they define a common path or typical paths and a set of identifiable performance levels for the development of knowledge and skill in core school subject areas, afford the possibility of defining standards by choosing which of the performance levels should be deemed adequate for the kind of functioning that should be expected of, say, a high school graduate. 
In addition, the empirical work necessary to justify that a hypothetical learning progression provides an adequate description of the ways in which students' understanding and skill grow over time should also in the long run provide evidence of the kinds of instruction and experience that are associated with enabling students to move along the progression and the rates at which they can do that, given their starting points. "Adequate (yearly) progress" toward that standard could be defined meaningfully in terms of identifiable movement along the progression's performance levels. "Adequacy" could be defined at least in part empirically through studies of the amount of progress needed to ensure that an at risk student located at an earlier performance level would reach the desired overall proficiency goals by the end of secondary school or by an empirically justified extension of that time. That amount or rate of progress in turn could be associated with empirical evidence about the levels of resources and pedagogical approaches that have enabled students who were at similar initial levels for a given age and grade to make progress at that rate. Furthermore, studies of learning progressions using alternative or innovative instructional regimes could be conducted to determine if they affected the rate or nature of student development, and, if they produced better results, the ultimate target could be raised with less concern that it would result in higher rates of failure. In this manner, research associated with learning progressions could result in higher standards that still would be fair for students and schools. ${ }^{2}$ There is currently little or no empirical justification supporting policy assertions about when schools should be successful in enabling all students to meet proficiency standards.

So standards could be set at realistically high levels and be empirically justified for most students while recognizing that, within reasonable limits, time and resources might have to vary to enable them to reach those standards. This would contrast with the current situation in which it seems that if students are to reach common grade level and graduation standards in common amounts of time and with similar resources, the standards have to be watered down to workable levels, but ones that probably are inadequate when judged by the demands of the world beyond school. Progressions offer the promise that standards based on them would be more transparent and harder to water down, since proficiency

\footnotetext{
${ }^{2}$ As this might affect accountability, if the evidence shows that most students can reach or exceed the level of the progression(s) judged to be adequate, having had specified kinds of instructional resources and time of the sort that schools might reasonably be expected to have at their disposal, then it is reasonable to hold both students and schools accountable for most students' reaching those levels. If the evidence shows that substantial numbers of students do not reach those levels within the time and with the instructional resources reasonably expected to be available, but that with identifiable adaptations of instruction and extensions of time, either within the normal school days and years, or reasonable extensions of years in school (or time after school), many more or almost all students can reach the desired levels, there would be an empirical justification for holding the same high expectations for all students and for holding schools and communities accountable for delivering the required and reasonable additional instructional resources and time. If the evidence shows that for some set of students, given their starting points and rates of progress, there is no known set of instructional approaches that enable them to reach the desired levels of the progression within the reasonably available time, then that suggests that the system needs to search for approaches that will do better and that in the interim the expectations for students should be that they progress as far as possible along the same progression expected for all students and that the system should be held accountable for tracking students' progress and making every effort to learn how to enable them to reach the desired levels. Accountability should not punish schools and teachers for failing to do what no one knows how to do, but it should hold them responsible for knowing where their students are, for doing the best we know how to do, and for joining in the effort to learn how to do better.
} 
would be referenced to identifiable and understandable levels in the progressions and could be clearly compared with descriptions of the levels above and below them. Students who had not reached or exceeded proficiency could be characterized in terms of the levels they had reached, rather than described simply as being at "basic" or "below basic" levels. The clarity of the descriptions of the levels in learning progressions and the learning performances associated with them would also offer the possibility of gathering much stronger empirical evidence of what students who had reached a given level would be able to do in terms of applying their knowledge and skill to real world problems or to further learning. This again would provide a contrast with the obscurity of current standards' proficiency levels and the lack of evidence that students who, say, just meet proficiency standards on current state assessments would be seen by competent observers to be proficient in any real world sense.

A progressions approach also suggests a way to deal with another of the problems with our current approach to setting standards. This problem stems from the fact that standards often define grade-level expectations in terms of the content to be taught. But that means that teachers are faced with a situation in which they are expected to teach the same concepts and facts to all of their students, even while they recognize that their students will differ quite widely in the ways in which they can reason with and argue about those concepts and facts. The performance standards associated with this content, and the assessments associated with them, tend to confound knowledge of facts and vocabulary with scientific practices in ways that make it difficult to know exactly what is being assessed or how to respond constructively to students' results to help them improve. By treating the development of concepts and practices as analytically distinguishable, but intertwined, pathways (each of them being what we will define below as "progress variables"), progressions can make this tension explicit and provide a basis for describing and assessing the empirically observable combinations of concepts and practices that actually show up in students' understanding and in their work.

In practice this might mean that a teacher covering a particular topic in a grade would be able to see that some of her children were thinking about that topic in ways characteristic of "earlier" consolidations of the related content and practices progressions. If students were not able to show progress on practices in the context of that particular topic while she was teaching it, having the issue clearly identified in terms of the parallel progressions should make it possible for the teacher to help the students to focus on those practices in the context of their work with subsequent topics or content. The point is that the progressions can make the interactions between content and practices explicit in a way that current standards and assessments often do not, and this in turn provides direction for more effective instructional responses. We also would observe that the fact that progressions can make these distinctions explicit provides a much firmer grounding for thinking about skills (as in "Twenty-First Century Skills") in ways that are instructionally relevant, rather than thinking of them as things that can somehow be taught in their own right, independent of particular content.

\section{Improved Curricula}

When it comes to curriculum, our main point is that everything we have just said above argues that learning progressions could provide much more useful frameworks for devising specific curricula than are provided by most current standards documents. To repeat-that is because progressions would be rooted in evidence gathered from real 
students in the course of instruction with real teachers, and provide descriptions of students' progress that specify the particular instructional approaches, or the range of approaches, that were associated with the described progress. Because they would be grounded and tested in real teaching and learning situations, they also hold the promise of providing more realistic pictures of the kinds of progress or growth students are likely to be able to show within the time and particular resource constraints available to schools and teachers. They could support realistic and parsimonious planning for what would be required to meet the needs of a given student population, and help to guide the development of fairer and more realistic accountability provisions for schools, teachers, and students. If learning progressions were derived from and tested against evidence of the association between the kinds of progress students make and the kinds of instruction they have experienced, as we are suggesting they should be, then they could provide a basis for specifying "curriculum frameworks" for determining what, and in what order and intensity, specific content and skills should be taught, They also would provide a basis for designing "instructional regimes" that would specify ways of responding pedagogically to individual students' or groups of students' particular stages of progress and learning problems. In this case we would be tempted to argue that we would not need a separate superstructure of "standards" at all - except for the function of identifying within the progressions or frameworks the levels that substantially all children would eventually be expected to reach.

\section{Improved Assessments}

Designing and validating assessment instruments focused on the identified levels of progress is part of the process of developing a learning progression. Developers of learning progressions specify learning performance indicators that exemplify how students are likely to think and what they are likely to know, understand, and be able to do (along with their likely misunderstandings as well) at particular points along the progression. These performances encompass levels of understanding and use for both conceptual knowledge and scientific practices that generate that knowledge-practices such as designing investigations, constructing models, critiquing explanations, making scientific arguments, or applying scientific concepts to non-standard problems. These learning performance indicators operationally define the levels of increased understanding and application that most students are likely to pass through on the path to achieving the learning target at the top of the learning progression. Testing the construct validity of learning progressions requires that assessments be designed to report validly on students' levels of progress in terms of the student performances associated with these learning performance indicators.

This requirement to discriminate reliably and validly between levels of performance rather than to discriminate among students-or to order them somehow-represents a subtle, but quite fundamental, shift in the purpose of assessment. Development of learning progressions requires extensive dialogue among science educators, learning scientists, and measurement specialists and should bring these communities together to develop more aligned curricula and assessment. In fact, in several of the cases we examined, assessment experts are working closely with science educators and learning scientists to design assessments that measure different levels of student understanding of specific science content. These assessments are intended to measure use of scientific practices (such as providing explanations or models or designing experiments to test them) as well as understanding of core concepts (such as the conservation of matter, or buoyancy) and therefore define in explicit terms how students at each level will express their 
knowledge and skill. The learning performances defined in the progressions typically would require students to engage in more complex tasks and provide teachers with richer insights into student thinking than the assessment items typically used in state assessments.

Most importantly for the development of better assessments, learning progressions characterize how student performances change over time and describe how thinking will develop over time relative to specific starting and ending points. Thus the assessments based on a progression should provide more useful information than conventional standardized norm-referenced tests do about student progress toward specific learning goals. The assessments derived from learning progressions are likely to provide information that is more easily interpreted by teachers and potentially allow them make better informed and more precise decisions about student needs and how to respond to them instructionally.

\section{Improved Instruction}

Having a clear conception of the likely stages of students' progress ought in itself to be useful in guiding teachers on their instructional goals and choices, particularly as those would be reinforced by curricula and assessments informed by progressions. But the evidence generated during the development and testing of the hypothetical learning progressions concerning how they are influenced by instructional choices and experiences should provide even more direct support for teachers' choices about what to do when they see evidence of how their students are progressing and what particular difficulties they are facing. The empirical investigations that are required to inform the development of progressions and to confirm their usefulness also should provide the grounding for the pedagogical content knowledge that teachers need to guide their instructional choices. Teachers' acquisition of that knowledge could of course be facilitated through participation in pre-service education or professional development experiences that would be informed by, and designed in accordance with, the research that supports the development and ongoing validation of the progressions.

The development of learning progressions in science and the gathering of evidence to support them is still at an early stage, and there is much to be learned about their value as guides to development of curricula, assessments, and instructional tools, as well as about the consequences of their use for improving students' learning. More learning progressions need to be developed to flesh out a map of progressions for $\mathrm{K}-12$ science. What we have tried to do in this section is to provide a more detailed argument about the ways in which the development, testing, and use of learning progressions could provide the basis for constructing a more coherent and effective instructional system for our schools. CCII hopes that this argument can help to make the case for the kinds of investments that will be required if this potential is to become a reality. 


\section{Recent Work on Learning Progressions}

Before the term learning progression was coined, developers of assessments were undertaking similar work. The NRC report, Knowing What Students Know (NRC, 2001), explored advances in both cognitive and measurement sciences and made recommendations about educational assessment that were subsequently incorporated into work on learning progressions. For example, the NRC committee recommended that assessment design be informed by models of cognition and learning - which should be informed by empirical studies of learners in a domain - and that instruction, curriculum and assessment be aligned. The NRC report notes that if descriptions of how learning develops over time can be obtained, "assessments can be designed to identify current student thinking, likely antecedent understandings, and next steps to move the student toward more sophisticated understandings" (NRC, 2001, p. 182). This was essentially a call for the development of learning progressions. Work along these lines was undertaken by Mark Wilson and his colleagues at the Berkeley Evaluation and Assessment Research (BEAR) Center (Briggs, Alonzo, Schwab, \& Wilson, 2006; Roberts, Wilson, \& Draney, 1997) who approached the development of assessments by developing detailed descriptions of how student understanding of specific science content might develop over time. They then measured student progress by focusing on progress variables which they defined as the critical dimensions of knowledge or skill that were being taught.

During the same period, two other research programs were addressing some of the important conceptual elements of learning progressions although they did not initially use the term. Lehrer and Schauble (2000) conducted studies of classroom interventions in elementary classrooms focused on data modeling and model-based reasoning in science. They developed instructional units that engaged first graders in defining and measuring attributes of living organisms (such as mold growth or flower bulb growth); engaged second and third graders in developing representations and describing patterns in data about living organisms (such as the growth of Wisconsin Fast Plants); and then engaged fourth and fifth graders in conducting experiments and exploring qualities of resulting distributions in living systems. As a result of these carefully scaffolded instructional experiences, they found that third- and fifth- grade students developed more sophisticated reasoning about living organisms and could engage in scientific inquiry at higher levels of sophistication than typical elementary students. After experiencing these carefully scaffolded instructional experiences, students were able to ask more sophisticated questions and developed more sophisticated means of measuring and analyzing data than were observed among students in traditional programs of study (Lehrer \& Schauble, 2000).

A second program of study by Schmidt and colleagues examined the relationship between the content and structure of curricula and student achievement in a dataset collected as part of the TIMSS international science assessment. Valverde and Schmidt's (1997) study concluded that countries performing well on TIMSS, such as Singapore, had more 
focused and coherent K-12 science curricula. Their curricula had fewer topics, less repetition of the same ideas, more careful articulation of topics across the grades, and more connections among topics to allow students to build more sophisticated understandings. In contrast, U.S. curricula typically covered more topics, at more superficial levels, repeated topics more frequently across grades, and the sequence of topics often lacked a logical structure that would allow students to continue to work on and develop ideas across their primary and secondary school careers.

The term learning progressions, in the context of science education, first received attention in a 2005 NRC report on the design of science achievement tests for grades K-12. This committee called for better coherence and alignment among assessments, curriculum, and instruction, and mentioned learning progressions as potential tools for achieving the kind of alignment that was needed. To test and promote this idea, the NRC panel asked two committees of education researchers to develop sample learning progressions to demonstrate their feasibility and potential value. One committee developed a learning progression for the atomic molecular theory of matter, and the other developed one for the theory of evolution (Smith et al., 2004; Catley et al., 2005). In a subsequent article, Smith and her colleagues (2006) defined learning progressions as sequences of successively more complex ways of thinking about core ideas. They constructed progressions by defining the successive levels of increased sophistication in thinking that students might be expected to demonstrate as they learn about matter in school (Smith et al., 2006). Each of the two committees submitted a concrete example of a learning progression, and tried to demonstrate how they might be used to influence the development of better aligned assessments, curriculum and instruction. Their efforts stimulated further work on the development of learning progressions in science.

The learning progression on the atomic molecular theory of matter covered a large grade span (i.e., K-8), and illustrated how standards, curriculum, instruction, and assessment across a significant portion of schooling could be informed by this kind of tool. Smith et al. (2006) posited that three big ideas from chemistry were central to understanding the nature and behavior of matter and that students should develop increasingly more sophisticated understanding of these three ideas across the grades. The three central ideas were:

- the notion that all objects are constituted of matter, which exists in different material kinds, and that objects have properties that can be measured and depend on the kind of matter present;

- the notion that matter can be transformed, but never created or destroyed; and,

- the notion that we can learn about the world through measurement, modeling, and argumentation.

Note that two of these big ideas refer to scientific concepts while the other refers to processes or practices within science. These three ideas were then broken down into smaller components, or sub-ideas, that operationally defined their meaning. In total eight component ideas were identified. This focus on eight sub-ideas stands in stark contrast to the dozens of statements about matter included in most state and national standards which define expectations about what students should learn as they move through elementary and middle school. The eight key sub-ideas identified by Smith and her colleagues were drawn from research on how students learn concepts related to matter as well as from examination of the national standards in science, whose authors had identified the fundamental science concepts and principles by examining each discipline of science. 
Smith and her colleagues argued that these three core ideas and eight sub-ideas were broad enough and fundamental enough that students could begin to learn them in early elementary grades but continue to develop increasingly sophisticated ways of thinking about them as they moved from kindergarten to eighth grade. The sub-idea that mass and weight are conserved across a broad range of transformations can be used to illustrate this point. For this sub-idea, Smith and colleagues (2006) proposed that:

- at the K-2 grade level students should understand transformations (such as reshaping and breaking into smaller pieces) where the amount of stuff and weight are conserved despite the apparent physical changes;

- at the 3-5 grade level students should understand that matter continues to exist when broken into pieces too tiny to be visible and that matter and weight are conserved across a broad range of transformations (e.g. melting, freezing, and dissolving); and,

- finally at the 6-8 grade level, students should understand that mass and weight are conserved across chemical changes, dissolving, phase change and thermal expansions (this level of thinking corresponds to a science standard described in documents such as the National Science Education Standards (NRC, 1996) and the Benchmarks for Science Literacy (AAAS, 1993).

Given such a curriculum, student thinking would be expected to become more sophisticated over time, there would be a high degree of coherence across the grade levels, and while new ideas built off of previous learning, there would be little repetition of exactly the same ideas. However, the authors did not indicate what kinds of learning experiences would be needed for students to move from one level to the next. In this example, student thinking shifts from the concrete and observable to more abstract and invisible concepts that rely on modeling. The progressive development of the other seven sub-ideas is described in similar fashion.

Smith and her colleagues (2006) specified the learning performances that describe how students' understanding of the big ideas should be demonstrated. These were a combination of content standards (e.g., the aforementioned big ideas) and scientific practices shown to be beneficial to developing deeper and more complex understandings (e.g. taking measurements; constructing arguments using evidence, analyzing data, making predictions, critiquing and revising explanations and models, etc). It should be noted that in this progression, as in others, some scientific practices are identified as big ideas or a progress variable in their own right, but they also show up as a component of the learning performances that typify the levels in the content progress variables. Practices are seen as being crucial contributors to deepening students' understanding of content, and this entanglement of practices and concepts seems to be an inescapable aspect of the development of full scientific understanding (Krajcik et al., 2008). Treating practices as progress variables seems to be a useful abstraction, and it certainly ought to help to focus the attention of teachers and researchers on the role they also play in the performances and assessments used to track conceptual development.

The learning performances specify in cognitive terms exactly how students at a particular stage of progress (or achievement level) would be able to demonstrate and show their understanding of the concepts about matter in the classroom. For instance, one learning performance for grades 3-5 recommends that students predict and explain what happens to the weight of an ice cube during melting. 
It is worth noting that the development of this learning progression was heavily influenced by a review of research on how students learn about matter which included studies of students' naïve conceptions of matter. For example, researchers have found that young students have difficulty with the notion that gases have mass and volume, and often believe gases are weightless. The developers of the learning progression also drew on findings from research on instructional interventions that supported reasoning about matter such as interventions that had engaged students in argumentation and explanations of chemical phenomena based on evidence, or interventions that engaged students in using and critiquing models of chemical phenomena.

In summary, Smith and her colleagues (2006) generated a learning progression that specified in great detail what students could learn about matter, given adequate instruction, and in what sequence, across the grades of kindergarten to eighth. They also suggested, through the specification of learning performances, the types of tasks students might engage in to demonstrate their understanding of matter at different ages. Furthermore, these learning performances provided the basis for developing and validating assessments that could be used to assess student understanding of matter. If used in classrooms, validated assessments would provide teachers with research-based diagnostic instruments that would be tightly aligned with the recommended instructional sequences, and which could inform them about how students were thinking about matter and whether their thinking was consistent or inconsistent with what should be expected at that point in the developmental sequence.

The second learning progression commissioned by the NRC was developed by Catley, Lehrer, and Reiser (2005), and covered evolution. It is similar in design; it focuses on a few central concepts or ideas, specifies learning performances that combine scientific practices with important concepts, and includes assessments linked to the learning performances. The researchers who developed this learning progression found there was little research related to young children's understandings of evolution; however, they found considerable research on children's understanding of biology more generally, and about organisms, in particular, along with a growing body of research on how young students reason about variability and distribution (believed to be a key component in student thinking about changing populations). Therefore, the development of this progression began with logical conjectures drawn from this body of research about how students might develop more sophisticated understanding of evolution. Researchers are conducting studies to gather the empirical evidence needed to test and refine the progression.

These two papers provided concrete examples of what learning progressions in science might look like, and the one on matter was used as an example of a well-designed learning progression in the subsequent 2007 NRC report on K-8 learning in science, Taking Science to School. This NRC report emphasized the potential value of learning progressions, highlighted them as an important tool for developing more coherent science standards, assessments, curriculum, and instruction, and generated increased interest in their development. NSF funded a set of research projects to develop learning progressions following the $2005 \mathrm{NRC}$ report and has continued to fund research on learning progressions since that time. NSF has recognized the potential value of learning progressions; and, in addition to funding their development, they have supported meetings of researchers to discuss them and to build increased capacity for their development. These activities have increased awareness of learning progressions and stimulated further interest in their development and use. When CCII launched its meetings about science learning 
progressions in May of 2008, NSF had funded 10 projects, and individuals from half of these projects participated in the panel meetings. Researchers on the panel who were funded by NSF included: Joseph Krajcik, Mark Wilson, Brian Reiser, Andy Anderson, Leona Schauble, Richard Lehrer, Amelia Gotwals, Alicia Alonzo, and Ravit Duncan (see a full list of attendees in Appendix A). By December 2008, NSF had awarded at least 15 grants to different groups to develop or study learning progressions in $\mathrm{K}-12$ science. 


\section{Where Does the Work Stand?}

In the process of preparing for the panel meetings and developing this report, CCII staff gathered information on learning progressions in science that either had been completed or were under development. Table 1 in Appendix B lists all of the learning progressions projects that were identified by CCII staff, and identifies the topics covered, who developed them, the specific ideas and/or practices addressed, their grade spans, the stage of their development, and their purpose. This table provides a quick overview of the work done on learning progressions in science. The list is probably not complete as there is undoubtedly work underway that was not identified by talking to the CCII panel members or examining lists of grant awards. Many of the learning progressions on this list were reviewed and discussed at the science panel meetings hosted by CCII.

Examination of these learning progressions and others reveals some similarities and differences. First, the similarities; all or almost all of the learning progressions listed in Table 1:

\section{Similarities}

- address fundamental concepts or practices (e.g. atomic molecular theory, carbon cycling, evolution, constructing models, constructing explanations). A fundamental concept or principle within a scientific discipline is one that explains a wide range of natural phenomena and serves as an important building block for developing other scientific knowledge. Focusing on fundamental concepts would allow the paring down of the existing standards and curricula, and give teachers more time to work with students to build deeper, and more integrated understanding of these core concepts because they would have fewer standards to cover.

- describe the development of increased sophistication in students' understanding and thinking. The developers focus on how students develop more sophisticated ways of thinking about fundamental concepts over time and have identified levels or plateaus in their development which they define with specific performances or achievement levels. ${ }^{3}$ These changes in student thinking may foreground the development of conceptual knowledge or the development of scientific practices, although most of the developers contend they are studying student thinking in contexts where content and practices are closely connected.

\footnotetext{
${ }^{3}$ Some contend that learning is continuous, and that developers of learning progressions attempt to artificially segment the continuum for measurement purposes. This is an empirical question, and perhaps less important than it seems because the organization of school calendars requires segmentation as well.
} 
- are based on reviews of findings in research literature about how children understand and learn the specific content and practices contained in the progression.

- are being validated empirically. However, with one exception, the developers of the learning progressions examined in this report have not yet had time to gather and analyze the evidence needed to validate their progressions. The exception is the work on buoyancy, but that work was designed as a kind of demonstration or proof of concept, and it deals with a more limited span than progression developers would typically try to encompass. Being validated should not be confused with being proven; it simply means that a progression has been tested empirically and the model of growth that it offers was supported by the data. It remains a hypotheses about the pathway to proficiency. When developers refer to validation they mean construct validity, that is, the pathway(s) in the progression with its levels of achievement is supported by empirical evidence indicating that students in general do progress through the specified levels of thinking, moving from lower to higher levels as described in the learning progression. However, consequential validity is also important; this refers to the impact the use of the progression has on learning outcomes.

The review by the CCII Panel also revealed some striking differences in the existing portfolio of learning progressions in science such as:

\section{Differences}

- the grain-size and scope of the content and practices covered. The concepts vary in their importance and breadth. For example, some developers describe changes in student thinking about topics as broad as carbon cycling or molecular biology. Some focus on narrow topics such as buoyancy. The level of detail provided about the observed changes in student thinking also varies. Some progressions describe broad, general changes in thinking and define as few as four levels; others specify small changes in thinking and include many levels.

- the attention given to science practices. Some foreground the progression of development of student use of practices such as model building, and construction of explanations while others emphasize the development of understanding of scientific concepts.

- the time spans they cover. Most do not cover the entire K-12 grade span. A few cover only a month or two of instruction. Most span just two or three years, some span $\mathrm{K}-8$, and a few span $\mathrm{K}-12$.

- the information that is included. Some include theories of instruction which specify the instructional contexts, activities, tools, representations and forms of argumentation to be used. Some developers also include 
theories of professional development, which spell out how teachers are to be supported. In contrast, other progressions provide no information about instruction, and provide only a framework for how students' thinking progresses, along with corresponding assessments that can track students along the progression.

- the approach taken to validation. Some progressions are linked to a specific curriculum and are being tested by collecting student work from classroom in which the curriculum is being used to specify the expected achievement levels; these studies tend to be longitudinal, with changes in student thinking and ability tracked over the course of a few weeks, a year, or a couple of years. Others are not associated with specific curricula, but are more general in their formulation and use cross-sectional data based on student interviews and assessments in many classrooms using varied science curricula to develop achievement levels. In the latter cases, the achievement levels are subsequently being validated with studies of targeted classroom interventions.

- the quality of the research base on how children understand the key concepts in the progression. For instance, some learning progressions rest on solid and extensive findings on student learning as well as careful examination of the logical structure of disciplinary knowledge in the domain covered by the progression. In contrast, others rest on rather limited amounts of empirical research on student learning or less consistent or less rigorous bodies of research. The latter are often supplemented with knowledge drawn from inferences made from research into learning in science in general, or rely more heavily on professional judgments about the development of student thinking.

Such variation in approach is typical of new fields of work where there is not yet agreement about the best methods to be used for development or validation. Review of the existing progressions revealed that most of them had not been extensively tested. Validation would increase our confidence in the models of teaching and learning provided by a progression. There also is no track record that would lead to preferences about approaches to development or validation or even a set of criteria for what would be an acceptable learning progressions. The work on progressions in science is in its infancy, and development is an iterative process, in which the progress variables, learning performances, assessments, and levels of achievement are continually being refined and revised.

\section{A Close Look at Three Learning Progressions}

Tables displaying some of the detail from three learning progressions are presented in Appendix C: one focused on buoyancy developed by Richard Shavelson and his group, the Stanford Education Assessment Lab, and subsequently revised by Kennedy and Wilson; one developed by Smith and colleagues focused on the atomic molecular theory; and, one developed by Mohan and colleagues focused on the carbon cycle in ecological systems. The tables outline how the focal science concepts may become more sophisticated over time. These three progressions illustrate both the potential utility of these tools, and the current variation in the scope, level of detail, and methods used. Here we offer some 
brief commentary on each of these progressions to draw the reader's attention to their distinguishing features.

Example 1: Buoyancy

Kennedy and Wilson (2007) developed a learning progression consisting of an assessment system aligned tightly to an elementary curriculum on buoyancy. The curriculum unit, consisting of 12 investigations, is a part of the Foundations Approach to Science Teaching (FAST) series in the physical sciences (Pottenger \& Young, 1992). This progression highlights many of the features that good progressions possess: it targets an important concept; it describes the ways in which student thinking becomes more sophisticated over time; and, it identifies the misconceptions and productive prior conceptions that students hold en route to a more scientifically acceptable understanding. While not included in the table presented in Appendix C, the developers specified the ways by which students would demonstrate their understanding (i.e., through the analysis of data and the construction of written explanations for why things sink or float).

Two progress variables were developed one for "why things will sink or float" (the WTSF progress variable) and one for "reasoning." The WTSF progress variable characterizes how students' understanding of sinking and floating develops, beginning with naive thinking that considers shape and size, to more sophisticated conceptions that consider mass or volume, and eventually to even more sophisticated conceptions that consider density and finally the relative densities of the object and the medium. The reasoning progress variable considers the quality of the justifications students provide when explaining why something is floating or sinking and describes a progression from explanations offering only observational statements to those including some relationships between the object properties and its behavior, and eventually to more sophisticated explanations that include physical principles that account for the behavior of the object. This framework was initially developed by looking at the learning goals of the curriculum and then revised, refined, and validated using the student assessments linked to the curriculum. The final product is an empirically-based framework that describes how student thinking develops across the 12 investigations.

What is strikingly distinct about this progression is its scope, and this became a subject of debate among the CCII panelists, until the developers made it clear that they had chosen this more manageable scope in order to demonstrate what a full application of the BEAR assessment system to a progression might look like. Buoyancy is a narrow topic, and while it is a concept that allows students to explain a range of phenomena in the natural world, it is a small slice of what students need to know to become scientifically literate. The progression is focused on the study of one concept over a few months. This is in direct contrast to the broader topics of the two other examples described below (and in Appendix C) which focus on the carbon cycle in socio-ecological systems and the atomic molecular theory respectfully. On the other hand, this framework has a 
tremendous amount of utility for teachers using the curriculum and helps them understand where their students are in the development of understanding of buoyancy and what is needed to move them to the next step. Its empirical nature and linkage to a specific curriculum allow educators to make informed evaluations of student learning about a specific topic of science.

\section{Example 2: Atomic MolecularTheory}

This framework was an early attempt by Smith, Wiser, Anderson, and Krajcik (2006) to describe what a learning progression looks like. While it differs in some respects from the more current work, it focuses on a core idea in science-the atomic molecular theory. Atomic molecular theory helps to explain a vast range of phenomena in the natural world that students explore in chemistry, biology, earth science, and physics, therefore it is an important part of the school science curriculum. The progression is focused on a few important ideas, principles, and practices thought to be essential to developing the atomic molecular theory to a higher level of sophistication by the 8th grade (e.g., the notion that matter is conserved; the notion that matter is composed of small particles; and the practice of collecting and analyzing quantitative measurements). This progression also includes hypothesized levels of sophistication (or levels of achievement) at different age bands (K-2, 3-5, 6-8) and it suggests assessments that could be used to examine student thinking and reasoning about matter (e.g., predicting what happens to gas particles in a syringe when the syringe is compressed and volume inside is decreased; explaining by using written representations of what happens when equal volumes of water mix with equal volumes of alcohol-a counter intuitive case for most students with surprising results for total volume and total mass). These assessments are tightly aligned with the content and learning performances, and could be used to validate the progression. These assessments could serve either formative or summative assessment purposes.

The progression had not gone through a validation process to confirm its framework at the time of its publication. However, teams of researchers are working to validate different parts of the progression separately. Thus, it will be refined and revised through analysis of empirical data on student thinking.

This progression in its original form looked rather like a standards document, although it was organized in a more deliberate fashion. However, the identification of the science ideas, the order in which they are introduced, and the definition of achievement levels was informed by research on student learning about the nature and behavior of matter. In fact, the commissioned paper in which Smith and her colleagues (2004) presented the progression lists the naïve student conceptions identified by researchers that helped to inform the hypothesized progression.

Krajcik and his colleagues (2008) have developed a curriculum that aligns with this progression and are studying how students' development of the particulate matter model changes over the course of a few years. This type of longitudinal work will be used to revise and refine the progression. 


\section{Example 3: Tracing Carbon in Ecosystems}

In this progression developed by Mohan, Chen, and Anderson (2009) $)^{4}$, the focus is on the flow of organic carbon through socio-ecological systems. The progression describes the development of student thinking about how living systems generate and transform organic carbon through processes such as photosynthesis, digestion and biosynthesis as well as how organic carbon is oxidized by cellular respiration, degradation and decay and by burning in engineered systems (or man-made systems). Discrete levels of sophistication are described.

Like the Smith et al. progression, this work was informed by research on naïve understandings of matter and ecological processes as well other research on cognition. But unlike the Smith et al. (2006) progression, it has been heavily influenced by empirical data collected from paper and pencil assessments and clinical interviews. The assessments required students to provide explanations or make predictions (or accounts) for different phenomena related to the transformation of organic carbon.

This example provides a coherent description of the progression of student thinking from elementary to high school about how organic matter is generated, transformed and oxidized. Different levels of student reasoning about the phenomena are described, starting with reasoning that reflects naïve thinking and relies on informal cultural models and myth; shifting to reasoning that recognizes some hidden mechanisms; then shifting again to consideration of some mechanism, but the descriptions of the mechanism are limited; and, finally, reaching a level where students begin to use the atomic-molecular model. The research group had hypothesized even higher levels using quantitative reasoning, but they did not observe this level in their sample of students, and thus those levels are not filled in and refined in the progression because they have no empirical data to support them.

In addition to the patterns of thinking, this group identified common errors that characterized reasoning at the different levels in the progression. This progression is supported by empirical data collected by interviewing students at different age levels at the same time, as opposed to tracking individual students across time. This cross-sectional approach differs from how others are validating progressions, but the result is a refined progression spanning many grade levels. The empirical evidence also allows detailed description of student thinking. They also were able to identify progress variables; in this case, the progress variables were plant growth, animal growth, exercise/ breathing, decay, and burning. Although not apparent in the table, the group drew the progress variables from analysis of the student data (Anderson, personal communication, February 2008.

Another important feature of this progression is that the students from whom data were collected were not exposed to a specific curriculum, but were representative of students going through the current system. Therefore, this progression is not linked to any specific curriculum or instructional approaches.

\footnotetext{
${ }^{4}$ The example described here reflects earlier work on this progression. A more current version of the progression is currently in press.
} 


\section{Elements of a Good Learning Progression}

Some of the participants on the panel who had not been involved in developing progressions were less clear about what was distinctive about learning progressions and how they differed from more conventional approaches to defining the sequence of topics in the $\mathrm{K}-12$ science curriculum, such as scope and sequence charts, curriculum frameworks, and strand maps. These same sentiments have been expressed at professional conferences when progressions have been discussed. There seems to be some general confusion over what is distinctive about the nature, content, and structure of progressions.

Part of the problem arises from the rather vague and limited definitions of progressions offered in the literature (Smith et al., 2006; NRC, 2007). To some degree, this vagueness has been intentional; some of the early developers preferred a loose definition so as not to constrain their work (Lehrer, Wilson \& Schauble, personal communication, spring 2008). However, lack of specificity and clarity raises the risk these new tools will be dismissed as "old wine in new bottles" and permits unacceptable products to be mislabeled as learning progressions. The latter could result in funders and policymakers reaching the conclusion that progressions will add little value to efforts to improve instruction, and that investment in the work will not pay off. The panelists encountered this problem when they attempted to evaluate some of the sample progressions included in a CCSSO commissioned paper by Margaret Heritage (Heritage, 2008). Researchers who had worked on progressions felt some of the examples labeled "learning progressions" did not meet their expectations. This led to a discussion about what their "standards" for a usable progression were. The panelists agreed that progress would be accelerated if developers were clear about what was distinctive about their work, and how progressions differed from other approaches to define the development of knowledge and skills in a curriculum. The panelists also felt it was important to be clear about how progressions should be developed. Specification of appropriate methods would help others understand how progressions differed from other approaches, and make it clear why they have potential to improve the effectiveness of science teaching and learning.

\section{The Panel's Working Definition}

After reviewing many, if not most, of the available learning progressions and discussing their features, the panelists agreed that a working definition was needed if the work was to be cumulative and productive over time. After considerable discussion and debate, a consensus emerged. This definition, we believe, builds upon and elaborates the one provided by Smith and colleagues (2006) and subsequently noted in the 2007 NRC Report on K-8 science learning. The panel's definition states:

Learning progressions are hypothesized descriptions of the successively more sophisticated ways student thinking about an important domain of knowledge or practice develops as children learn about and investigate that domain over an appropriate span of time. They must contain at least the following elements: 
1) Target performances or learning goals which are the end points of a learning progression and are defined by societal expectations, analysis of the discipline, and/or requirements for entry into the next level of education;

2) Progress variables which are the dimensions of understanding, application, and practice that are being developed and tracked over time. These may be core concepts in the discipline or practices central to scientific work;

3) Levels of achievement that are intermediate steps in the developmental pathway(s) traced by a learning progression. These levels may reflect levels of integration or common stages that characterize the development of student thinking. There may be intermediate steps that are non- canonical but are stepping stones to canonical ideas;

4) Learning performances which are the kinds of tasks students at a particular level of achievement would be capable of performing. They provide specifications for the development of assessments by which students would demonstrate their knowledge and understanding; and,

5) Assessments, which are the specific measures used to track student development along the hypothesized progression. Learning progressions include an approach to assessment, as assessments are integral to their development, validation, and use.

In addition, the panelists believe that learning progressions have some other common characteristics:

1) They are based on research in science education and cognitive psychology, etc.;

2) They are focused on foundational and generative disciplinary knowledge and practices;

3) They have internal conceptual coherence along several dimensions. The progress variables capture important dimensions of scientific understanding and practice and the achievement levels represent the successively more sophisticated levels of understanding and practice characterizing the development of student thinking over time. A progression may describe progress on a single progress variable or a cluster of related (and not just parallel) progress variables. Some progressions may provide an underlying cognitive account that leads to an expectation of the same or comparable achievement levels across the variables-a particular kind of "coherence." Such expectations of course require empirical verification;

4) They can be empirically tested;

5) They are not developmentally inevitable, but they may be developmentally constrained;

6) They are crucially dependent on the instructional practices provided for the students whose development is studied in the processes of development and validation. Targeted instruction and curriculum may be required for students to progress along a progression; and, 
7) There may be multiple possible paths and progress is not necessarily linear. It may be more like ecological succession. A learning progression proposes and clarifies one (or more) possible paths and does not represent a complete list of all possible paths. At any given time, an individual may display thinking/ practices characteristic of different points on the path, due to features of both the assessment context and the individual's cognition.

We note that other features were discussed and were considered essential by some panelists; these included the inclusion of a theory of instruction and a theory of professional development. However, there was no consensus that these features were essential elements of a learning progression.

Some of the salient features in the panel's definition are strikingly absent in alternative approaches to defining the sequence of teaching and learning in science. For example, strand maps, scope and sequence charts, and science curriculum frameworks often lack coherent and rigorous theoretical or empirical bases for their construction, as well as evidence that speaks to their validity. If their developers examine the evidence of how student thinking in science develops, it is done in a cursory or informal manner. More typically, they rely on logical analysis of the science disciplines or deductive analysis based on the socially desired outcomes (backward mapping). Sometimes they even fail to describe the expected changes in student learning in a coherent fashion. In many cases, they fail to specify how students would demonstrate their mastery of the content, and they seldom include aligned diagnostic assessment systems that would allow teachers to monitor student progress and intervene effectively if students fail to perform at expected levels.

Because learning progressions appear to "re-visit" student understanding of the core concepts that form their spine at multiple points, they are sometimes said to spiral. This leads to some confusion between progressions and spiraling curricula. While learning progressions might be used to develop a spiraling curriculum, spiraling is not their essential feature. It is the developmental pathway, the continua of development of understanding of the concepts covered by the progression, that is their key feature. Spiraling curricula do focus on the mastery of concepts over time, but they may lack a clear pattern of development, are seldom based on strong empirical foundations and typically lack the validation evidence characterizing progressions. 


\section{The Validation of Learning Progressions}

In both panel meetings a number of the participants raised the issue of how learning progressions might be "validated," - that is, how evidence might be gathered to test the internal robustness of the hypothesized progression (construct validity) and the hypothesis that the use of a suggested sequence is effective at producing the desired outcomes (consequential validity) - but we did not have a chance to reach any thorough conclusions on these issues. In subsequent exchanges we have found a basis for reaching greater clarity about the questions raised about validity. As we have argued above, we think a sensible way to think about learning progressions is to see them as being hypotheses (Stevens et al., 2009) about, or models for, the likely ways in which students' understanding of core scientific explanations and practices and their skills in using them grow over time with appropriate instruction and opportunities to learn. So, if these progressions are to be treated as hypotheses or small scale theories about how students are likely to learn, it seems to us reasonable to treat the issue of validation in the same way you would treat the development and testing of any scientific hypothesis or theory.

At one end, progressions start with entering knowledge of the children, which for young children might be the kinds of understanding of the natural world, and ways of thinking about it, that they are likely to have developed based on common human experience as mediated by the folk categories and explanations that are embedded in their culture and their native language. At the other end, progressions target an adequate understanding (that is one that would be recognized as a reasonable approximation of the way scientists currently see things) of how scientific disciplines explain and model the central phenomena of each discipline or interdisciplinary field and the ability to apply those understandings to solve problems and develop "new" knowledge. This target knowledge can also include an understanding of how science has come to and continues to build these explanations and models over time (i.e. an understanding of scientific practices: careful observation and measurement, devising and testing explanations against empirical evidence and alternative explanations, and the social norms of science - public logical argument, replication, verification, the willingness to abandon less effective explanations for better ones, and so on). We think there is no fixed rule for how to select the targets at the upper end. The point is that they are central and important for explaining significant phenomena in a field or for understanding how explanations are developed, and they are accessible to students within the normal course of their school experiences-the terms "big ideas" or "core concepts" are often used, as we have seen.Clearly questions of centrality, accessibility, and generativity are subject both to argument and to modification over time, especially with respect to accessibility; given that one hopes instruction will become more effective and make deeper understanding more accessible.

In between these two ends, the learning progression hypothesis suggests that it should be possible to identify some finite set of partial, intermediate, or approximate conceptions of the target explanation through which the students' understandings will build to reach 
that target. The strong version of the hypothesis would be that most students' understanding will move through these intermediate conceptions in roughly the same order, though perhaps at quite different rates (depending on instruction, ability, other experiences and exposure, including home opportunities, etc.). And for some more complex targets it may be that the intermediate steps involve collections of understandings that interact and support each other but which can be acquired in varying orders. The point would be that the hypothesized progression should be able to specify some way of identifying whether students have acquired each of these conceptions, as well as whether they can be expected to occur in some order or at some time in relation to each other. It also is reasonable to think of any particular progression as being made up of sets of component progressions, each of which could be specified in a similar way. And as these subprogressions approach the scale at which they might be covered within the course of an instructional unit, or a week, they are more and more likely to include specification of the instructional approaches that are most likely to move a student from one level of understanding to the next (or to undo particular misconceptions that have been identified).

For purposes of validation, all of the above descriptions of the elements of a hypothesized progression can be treated as propositions that can be tested as part of the process of validating a progression. As with any scientific hypothesis or theory, we should not think that testing these propositions can establish the validity of a progression once and for all. Rather, the best we can do is to increase our confidence that the progression is a reasonable account of the ways students are really likely to learn, while recognizing that it could be subject to substantial revision or replacement given new evidence and/or a more inclusive or compelling alternative hypothesis.

The process of hypothesis development and validation is presumably cyclical, but it can be assumed to start with close observation of how children and students at varying ages and with varying instructional and other experiences seem to think about and report their understanding of the phenomena that the educationally targeted scientific model will eventually help them to understand more adequately.

The observational methods that inform hypotheses about children's and students' developing levels of understanding can be quite diverse. At the early childhood/naïve level the methods tend to involve clinical interviews about what children think explains what they see or what happens in the world (Clement, 2000; Ginsburg, 2009; Piaget, 1976) and small scale laboratory situations that ask children to interpret (explain, attribute causes) particular situations or anticipate what might happen next (make predictions). This kind of work yields findings such as the idea that children tend to use qualitatively different language and explanatory structures with respect to persons, living things, and inanimate objects; or that it takes them some time and experience to recognize that other people can see things differently from themselves; that one's self or others can be mistaken; and, that some form of argument might be needed to resolve differences, etc. (Kuhn, 2005). 
There are five general approaches that tend to be used as starting points for the development of hypothesized progressions for characterizing how the understanding and skill of school age children and students grow beyond the conceptions they bring with them to school:

1) They can represent an extrapolation from current and conventional teacher and curriculum development practice, identifying a sometimes more parsimonious or coherent subset of what and when scientific concepts are now taught (this can include state standards and frameworks, expectations embodied in widely used assessments, and so on).

2) They can be based on cross-sectional sampling of student performance by age or grade, using existing assessments, or assessments created to try to reveal aspects of understanding or performance thought not to be tapped by existing assessments. This sampling also can include more open-ended interviewing or observation of students at work (and collection of the work they produce).

3) Students' work and performance can be sampled longitudinally over time, following the same students over the course of shorter or longer periods of instruction (and in both $\# 2$ and $\# 3$ students who have had differing instructional experiences might be contrasted).

4) They can grow out of closely observed classroom (or other settings) interventions designed to teach conventional or newly conceived understandings and skills, perhaps using new pedagogical approaches, and these can continue over varying amounts of time (and may involve comparisons with control or contrasting approaches).

5) They can be derived from disciplinary understanding of the structure of the key concepts in the discipline and the logic of their relationships and inter-dependencies (this also could be informed by knowledge from the history of science about how understanding in the discipline grew over time).

Clearly, in practice hypothesized progressions tend to grow out of reasoning based on some combination of many or all of these kinds of evidence. The development of a progression tends to be, and perhaps must be, an iterative process involving forming a tentative hypothesis, testing it against further observations of instruction and students' learning, revising it, checking it again, and so on. In many ways this process is indistinguishable from what would be done to assess the validity of a progression. Nevertheless, at some point researchers and developers who have been devising progressions come to some relatively stable view about the key steps students' thinking and skills are likely to go through (and perhaps the misconceptions or particular difficulties they are likely to experience along the way). At a minimum, a hypothetical progression then has to specify the ways in which you could tell whether a student had reached a particular step in the progression (often called "achievement levels"), or where he or she was in that process. That is, the description of the steps needs to specify what people working on learning progressions tend to call the "learning performances" that students would be able to demonstrate if they had reached a particular step (or in some cases also the misconceptions, etc. that they would have at that point, or that might impede their movement to the next level). Those normally translate into even more specific instantiations in terms of assessment items, classroom learning tasks, or assignments. 
Some working in this field would argue that the progressions, and the performances and assessments used to identify key steps in those progressions, should be pretty closely tied to curricular and instructional approaches that have been designed to promote student progress from point to point or that have evidence that they are associated with such progress. Among other advantages, knowing something about the instructional experiences students have had makes it possible to design performance expectations and assessments that tap more complex understanding and skills because one can make assumptions about the language and activities it would be fair to assume the students have been exposed to. Others prefer to work with data from students exposed to the normal range of curricula and instruction in our schools, so their progressions, learning performances, and assessments can have a more general application, but they also may be less precise, or have more difficulty in identifying and capturing performance, at the higher levels of the hypothesized progression. Whether instruction is specified or whether the progression involves a more general description of the likely stages of student progress, we think that the process of gathering evidence to validate or demonstrate the value of the progression should include attempts to specify what instruction the students have had, when their performances are being used as evidence that the progression describes the paths their learning has followed.

In any case, the logic of the progression hypothesis requires that when students' performances on the associated assessments, instructional tasks, assignments, etc. are sampled, one should not expect to see that students who were not able to demonstrate the expected learning performance thought to be earlier in the hypothetical progression were nevertheless able to succeed in performing in the way expected for a later point in the progression. If that should happen in more than a very few instances (some forms of performance may offer the possibility of succeeding "by chance," and that would introduce noise into this system), the progression or the design of the assessments, or both would have to be reconsidered and revised. ${ }^{5}$

There are quite sophisticated statistical and psychometric techniques that can be used to design and test the development of assessment items and exercises to see whether the item difficulties and student performances order themselves in ways that are consistent with the predictions implied by the hypothetical progressions (Wilson, 2005), and some form of this logic would seem to be essential for validating a progression-i.e. for increasing our sense of its credibility and usefulness. But there are other issues beyond the psychometric ones.

While a progression that is based primarily on evidence from cross-sectional sampling may be sufficient to inform the design of standards and assessments that are more

\footnotetext{
${ }^{5}$ There also are reasons other than this kind of chance noise that can cause students to show anomalous assessment performances, as for instance those who are able to perform at higher or later levels but who use earlier or inferior conceptions in a particular instance or exercise. This can be influenced by contextual variables such as relative familiarity of the particular content or degree of stress or time pressure. This may be less threatening to the progression hypothesis, but it has to be noted. It also is well known that students who demonstrate a familiarity with some scientific practice in one context may fail to show it in another. So a fully developed progression will have to take some principled stand on which of these kinds of anomalies are tolerable and which cast fundamental doubt on the progression. If this were just a summative assessment process, some of these issues might be handled just by giving credit for the best the student can do, but that is not the point here. It goes rather to the fundamental structural conception of the progression.
} 
instructive than many we have now, it does seem that the underlying logic of the concept would argue that the progressions should be seen in individual students' understanding as it grows over time-so that eventually there should be strong evidence from longitudinal studies that the hypothesized order of development holds. This is particularly true if the virtues of the hypothesized progressions for informing instruction are to be realized, since those virtues are likely to be seen most clearly when students' progress from step to step is observed very closely and attention is paid to what it is about the students' experiences that seems to help them in this progress. That kind of observation is likely to be crucial for building the kinds of pedagogical content knowledge that should be one of the beneficial outcomes of approaching instruction in terms of progressions.

Further, many of the ideas of progressions that are now being developed, particularly those that are strongly influenced by disciplinary ideas about what should be considered acceptable target understanding in the discipline's terms, set out expectations for performance at the high end that may be realized by only a few students, if any, in the course of conventional instruction in our schools. In that case it will be very hard to provide validation evidence for whether and how those conceptions of advanced performance are reached or how they can be assessed. That implies, in such instances, that students not only need to be followed over time but also that associated instructional interventions will have to be devised in order to test whether there can be "existence proofs" that the higher levels of progress can be reached by more than just a few unusual or talented students.

At the risk of complicating the issue even more, it also became clear in our discussions that, in representing students' progress as a relatively straightforward set of steps along a metaphorically linear path, learning progressions are making a useful but potentially misleading simplification. As we have discussed earlier, it is more reasonable to understand students as participating in multiple progressions simultaneously, and, in the case of science, these include related progressions in mathematical understanding, reading comprehension (which includes certainly general vocabulary and syntactical awareness), and the strands of scientific practices discussed above which, while they are pedagogically embedded in domain specific experiences, can be seen as having their own progressions. These all can hinder or facilitate the way specific understandings grow. This complexity complicates the picture of psychometric validation we painted earlier, since it reminds us that even if we think our hypothesized progression has a pretty clear logic, the assessment items and exercises we apply it to are likely to be affected by ("load on") these other progressions as well, and sorting out that more complex set of interactions requires more careful reasoning and implies an even more iterative approach to "validation."

\section{Examples of Validation Studies}

In order to clarify the different ways researchers are going about validating learning progressions, we will describe two approaches. First, as we described in detail in Section $\mathrm{V}$ above, Anderson and colleagues have embarked on a project to develop and validate a learning progression for the carbon cycle and the processes and principles involved in the creation, transformation, and decomposition of organic compounds in ecological systems. They started their work by identifying the important ideas that scientists use to explain phenomena involving organic compounds. These ideas can be found in the National Science Education Standards or the Benchmarks for Science Literacy and they explain how organic matter is created and transformed in ecological systems. These explanations include atomic molecular models that account for chemical change; the 
principle of conservation of matter; as well as models of glucose production in plants; digestion and biosynthesis in living organisms; and oxidation reactions when organic matter is decomposed or burned. These models and explanations constitute the upper level of reasoning about phenomena in ecological systems in their progression. The researchers then examined research on naïve understandings of the natural world in young children as well as research on linguistic understandings, to develop hypotheses about the lower levels of understanding of these phenomena. They conducted clinical interviews with students and collected assessment data across a large spectrum of ages (from elementary to high school) in order to collect evidence about how student thinking moves from naïve conceptions, which are populated with such vitalistic forces as "enablers" and "helpers," to more model-based conceptions that align more closely with scientifically acceptable models. The resulting theorized pathway defined discrete patterns of thinking specified in a particular order, and these patterns were then verified by collecting and analyzing cross-sectional data from student assessments and a few targeted classroom interventions at the middle and high school levels. These data were processed using sophisticated statistical and psychometric procedures which generated products such as Wright Maps and Item-fit maps and allowed the researchers to test whether the data from real students fit their hypothesized progression (Kennedy \& Wilson, 2007; Wilson, 2005; Wilson \& Carstensen, 2007). They looked to see whether the results on the assessment items were consistent with predictions from the progression, whether students functioning at specific achievement levels responded on specific items as the progression predicted, and whether students were making the predicted shifts in thinking. The evidence generally satisfied and supported their hypothesized progression about the ways in which student thinking changes from naïve to more scientific conceptions, and their results were consistent with previous research looking into how students understand matter and the flow of matter through ecosystems. Furthermore, the data tell a coherent story about how students' ideas about the flow of carbon through ecosystems change and become more sophisticated over time.

Duncan is taking a somewhat different approach to validation. Her approach relies on longitudinal studies of the progress of students using a specific curriculum. She has developed a learning progression for modern genetics and is now validating it. Like the Anderson group, Duncan began by identifying the core ideas and models that students need to develop to understand genetic phenomena in a way that approximates the modern scientific view; for this task, she drew on the National Science Education Standards and the Benchmarks for Science Literacy. She used these models to define the upper levels of understanding in the learning progression (e.g., the canonical scientific model that posits that genes are instructions for building proteins and proteins are the molecules that carry out various cellular functions, directly affecting the structure and function of cells, tissues, organs, and whole organisms). Duncan drew the entry levels of student understanding from previous research on students' conceptions of genetics and heredity as well as her own studies of classroom curricular interventions. According to these research findings, younger students, or more naïve students, have poorly developed notions of how genes influence physical traits and do not perceive molecular or cellular mechanisms as part of the process. When they learn more about genetics, they are likely to rely heavily on transmission models that consider the passage of genes and their influence on physical characteristics, but do not consider cellular or protein-based mechanisms that influence physical characteristics. Duncan concluded that students, 
if given the appropriate instructional experiences, could understand the role of proteins in shaping physical characteristics during the middle grades and could begin to develop more sophisticated ideas about how physical features emerge in biological organisms. She predicted that students, again with appropriate instructional supports, would then be capable of moving to the next level of thinking in which genes, proteins, and physical traits are linked (the targeted achievement level). Thus, the initial framework consisted of a few core concepts and some hypotheses about the ways in which students might develop understanding of how genes influence physical traits and specified how students would demonstrate their understanding of these genetics concepts (e.g., by constructed explanations of how genes influence traits or developments such as certain diseases or certain physical characteristics).

Duncan is now collecting empirical evidence about this learning progression by studying students who are being exposed to instruction using coherent inquiry-based curricular units that connect and build off of one another at the 7th and 8th grade levels and that require students to construct cellular and molecular explanations of biological phenomena. She is following individual students using these materials, administering pre and post tests and conducting clinical interviews and attempting to characterize their patterns and shifts in thinking to determine if they are consistent with the hypotheses in the learning progression. However, she also will be generating empirical evidence about the construct validity of the progression by collaborating with psychometricians to develop valid assessments and analyze the resulting student assessment data so that she can refine the progress variables and the levels of achievement in the progression. In the end she hopes to have a learning progression supported by evidence that will define a pathway through which students can achieve high levels of proficiency in understanding genetic phenomena and specify how student thinking changes in this domain from late elementary school to high school. It also should identify the instructional supports that can reliably help students make progress to higher levels of understanding before finishing high school.

\section{Consequential Validation}

Clearly, there is a good way to go before there are enough science learning progressions having strong evidence that they provide a credible description of the steps students are likely to go through in learning core understandings and skills so that such a collection of progressions could arguably provide the basis for designing a core school curriculum or for deriving from the progressions and the implied curriculum a better and more coherent set of state or supra-state standards and assessments. And it would be a step even further to claim that if such a set of progressions existed, they, and the curricula and assessments derived from them, would be able to inform teachers' understanding of their students' progress and problems in such a way that they could respond to that information with pointed instructional reactions that would enable their students to overcome their difficulties and stay on, or get back on, track, so as to meet learning goals, ensure higher levels of performance for all, and reduce gaps between the average level of performance of the student population as a whole and that of groups of students who were less likely to succeed in the past. But those are in fact the kinds of claims that are being made for the value of attending to and developing learning progressions. Those claims raise a general question of consequential validity for learning progressionsif we had enough of them, and they were well justified, would they in fact have these additional beneficial consequences for the education system? 
At this point, this is among the most hypothetical of questions. But it does suggest a program of further work that would be necessary to add other levels of "existence proof" to the demonstration that a particular progression works as it is supposed to. It would seem to be a reasonable requirement for the validation of the general progression hypothesis to suggest that, once there were a few well-warranted progressions covering at least a significant sub-set of the generally agreed goals of science education, an effort should be made to convince some set of states to array their standards for the relevant strand(s) of science content and skill learning across the relevant range of grades to match the appropriate achievement levels with the grades (or with the specified order) suggested by the progressions. If they would not do that on a state-wide basis at first, they might be encouraged to promote such an approach in some set of their districts on an experimental basis. In addition, curriculum developers, and providers of professional development, should be encouraged to design approaches to assessment (or a curriculum-embedded search for evidence of student progress and problems), and appropriate pedagogical and instructional responses, keyed to the progressions, and then this whole "regime" should be evaluated, perhaps in competition with "business as usual" or with compelling alternative approaches, to see whether students do significantly better, learn more, close gaps, and so on. If this sounds like a long and recursive process of validation of the progressions hypothesis, it is-but it clearly is consistent with the level of effort, and the time, likely to be required for progressions to prove that they are able to make a significant difference in the effectiveness of the American education system.

We think it is useful and instructive to recognize what actually will be required to test any adequately complex approach to reforming and improving instruction. The learning progression hypothesis is one such approach, and we have only begun to work out what will be required to make it a compelling one. But we do think that we also have begun to make the case that it is an approach that deserves to be taken seriously and that it would justify the investment required to give it a full chance to prove its worth. 


\section{The Research and Development Agenda}

The CCII Panel discussed the potential of learning progressions, the inadequacies and gaps in the work to date, and some of the challenges facing developers and potential users. They concluded that learning progressions held great promise as tools for improving standards, curriculum, assessment, and instruction. They agreed that it was important to advance the development of learning progressions in a manner that would produce the greatest benefit to educators in the shortest possible time. With this goal in mind, they recommended the following steps be taken by researchers, developers, policymakers, and education professionals:

- Share the available learning progressions

While the existing progressions cover only fragments of the $\mathrm{K}-12$ science curriculum, and most have not had extensive testing in classrooms, they still can provide useful information for groups working on state and national standards, and for developers working on curriculum and assessment as well. The existing progressions fill in only part of the picture, but, much like archaeologists reconstructing an ancient mosaic from fragments, standards setters and curriculum developers can do better work if they use the available progressions because they provide clues about the structure and sequence of the missing parts of the curriculum. ${ }^{6}$ At this point, the work tends to be in the hands of small groups of researchers who are working on completion or validation of the learning progressions they have developed. While some work has been shared through journal articles or conference papers, most of it is not readily accessible to those who need access to it.In this regard, it is encouraging that NSF is funding a series of working conferences to bring researchers working on the development and testing of learning progressions together to share their methods and findings. NSF, the American Association for the Advancement of Science (AAAS), or some other organization should create a website where this work, including work in progress, can be displayed with all of the proper caveats. Even incomplete and untested work can be helpful to those who are working on standards, curricula, and assessments.

\footnotetext{
${ }^{6}$ Some observers of the development of learning progressions would point out that the relationship between progressions and curriculum should be a two-way street. We already have implied that a good progression might be indistinguishable from a good curriculum framework, and it ought to be the case that well-designed curricula or curriculum frameworks-ones that are thoughtful about the ways in which students are likely to learn and what experiences should help them to do so-in areas where progressions have not yet been developed and tested would represent first-order approximations of hypothetical progressions for those areas. Students' experiences with such curricula would produce the evidence on which stronger progressions might be built (Lorrie Shepard, personal communication, April 13, 2009).
} 


\section{- Validate the learning progressions}

Funding agencies should provide additional support for research groups to validate the learning progressions they have developed so they can test them in practice and demonstrate their utility. Second party tests of the learning progressions may also be valuable. Studies are underway on some of the learning progressions listed in Appendix B, and it is important to complete these studies and make the evidence for the progressions available to those working on standards and on curriculum as soon as possible.

\section{- Create existence proofs}

An effort should be made to collect evidence that using learning progressions to inform curriculum, instruction, assessment design, professional development and/or education policy results in meaningful gains in student achievement. This evidence is needed to respond to skepticism expressed by various stakeholders about the value and significance of learning progressions, and to justify further investments in their development.

\section{- Identify the core science ideas to be studied}

Funders such as NSF should work with researchers and other relevant stakeholders to identify the core ideas that developers of the next set of learning progressions should be focusing on. Perhaps the step in this process should be to agree on criteria for selection of those ideas. This might help avoid contentious turf wars. The current work being undertaken by the National Science Teachers Association to identify "anchors" should inform the next round of work on learning progressions and help set priorities for funding this work. This would ensure that key gaps in the $\mathrm{K}-12$ science curriculum were addressed and the roster of available learning progressions would become more useful over time to developers of curriculum and assessments.

\section{- Invest in development of progressions for the central concepts} for K-12 science

This follows directly from the previous recommendation. Researchers should be encouraged to pursue development of progressions that address the core concepts and that cover larger grade spans. The result would be a collection of progressions with greater relevance to the needs of schools and to the needs of those who design instructional materials and assessments. This would encourage developers, state and district officials and school personnel to consider participating in research on progressions.

- Initiate work on the integration and connections among progressions Developers of progressions, and those who support their work, should consider collaborations with other developers to examine the connectivity and interaction across progressions, and to consider the implications of these interactions for curriculum. This would inform future work on learning progressions and help standard-setters and curriculum developers determine what topics are most generative of student understanding of science. Some will argue that it is too early to do this, but attempting to do it now will inform the development of the next generation of progressions and help set priorities for that work. 


\section{- Invest in the development of assessment tools based on learning progressions for use by teachers and schools.}

There is a fundamental difference between assessments designed to distinguish how students perform compared to other students on general scales of "achievement" or ability and assessments designed to distinguish among particular levels in the development of student knowledge and stages of sophistication in their understanding and ability to apply knowledge. We need assessment tools of the latter type to build and test progressions and to provide teachers with the diagnostic information they need to adapt instruction to meet the needs of their students.Adequate development of assessments of this sort, particularly ones that can track and report validly on progressions in longitudinal contexts, will require fundamental advances in psychometric methods, and that too will deserve increased investment.

\section{- Encourage collaboration between science education researchers,} assessment experts, and cognitive scientists

Inadequate communication among science education researchers, cognitive scientists, and assessment developers has been an obstacle to work on learning progressions. There is a need to build better understanding and collaboration across these domains. Funding agencies should seek to foster better and more frequent communication among these communities. They could sponsor programs that encourage the pairing of science education researchers and learning scientists with assessment experts. They might consider providing training on assessment development for science educators and cognitive scientists to enable them to work more closely with assessment experts, and vice versa.They also might consider funding centers to work on learning progressions and curriculum development where these different kinds of expertise might be convened.

\section{- Support more research on science learning}

We need research that enhances our understanding about how younger students learn and what they are capable of understanding.As noted above, we also need to understand more about how variations in cultural backgrounds and values affect the science learning of young children and how various classroom interventions can successfully accelerate their learning in science. However, this research should be tied to the development of learning progressions and not be completely disconnected from the development of these tools, as is the case for many current studies.

\section{- Study development of students from different cultural backgrounds} and with differing initial skill levels.

We desperately need to understand how to accelerate the learning of students who enter school with lower literacy levels and also to understand how cultural backgrounds and early experiences affect developmental paths. Researchers recognize that the pathways described by progressions are not developmentally inevitable and that there may be multiple pathways to learning a given idea or practice. They also recognize that prior experience, knowledge, and culture influence learning. Therefore, there is a need to explore how diversity affects the development and application of learning progressions, and whether, and how progressions can help us close achievement gaps in science.This is particularly relevant in urban populations or schools with highly diverse groups of students. 


\section{- Increase funding for the development and validation of learning progressions}

All of the above recommendations require funding. The present level of investment in this work is inadequate, and will not allow us to realize the potential benefits of these new tools. More money is needed to both fund more projects and give developers more time to construct and validate their learning progressions, especially if they are conducting longitudinal studies (two-three years is not enough time).

\section{- Encourage states revising their standards to consider the evidence} on learning progressions.

While the scope of the existing learning progressions in science and the evidence supporting the models of development they provide does not warrant mandating their use, states and districts revising their standards and trying to improve science teaching would benefit from considering the lessons they provide about the sequencing of the science curriculum, the inter-connections between conceptual understanding and practices, and the design of assessments.

\section{Why Should These Steps Be Taken?}

Learning progressions could help us shape education policies in the areas of curriculum, assessment, teacher education, and professional development and improve coherence and alignment across these policy domains.

Learning progressions will help curriculum developers rethink curriculum design so that it is more focused, better sequenced, and more coherent. New curricula should be consistent with established learning progressions and their key features should be incorporated into instructional materials (e.g., a coherent developmental sequence based on research, specification of learning performances, and valid diagnostic assessments that align with the learning performances).

Learning progressions can help education leaders (such as chief state school officers, superintendents, and state and district supervisors in charge of curriculum, assessment, and professional development) revise their standards, and rethink their assessments, curricular guides, classroom instruction, and professional development. Using progressions as a guide, they could improve the alignment among these policy tools and the instructional supports provided for teachers. By collaborating with researchers and developers on piloting materials and assessments linked to progressions, and by inviting researchers to collaborate on tasks such as standards revision, curriculum selection, assessment selection, and professional development, they can advance the work and contribute to our knowledge.

Learning progressions will help teachers rethink student learning, instruction, and assessment. They make it possible to improve diagnosis of student understanding, and serve as a tool to support adaptive instruction. Progressions could provide teachers with the frameworks, tools, and resources that would transform pedagogical content knowledge from a precious concept to an operational part of their practices.

Learning progressions could improve the design and operation of teacher education programs as well as the design of programs provided by local and regional professional development providers. For example, pre-service and professional development programs 
could be focused on the content that is covered by learning progressions, and consequently help teachers develop deeper understanding of the central ideas, how students typically master these ideas and develop more sophisticated understanding over time, and how to diagnose student progress and instructional needs.For example, progressions could be used to help novice teachers understand how student understanding develops over time and how instruction affects their development.Progressions would provide an informed framework for teachers to gain better understanding about how students' ideas develop; and provide them with assessments to track student understanding.

Learning progressions also can help to leverage the work done by science education researchers and learning scientists by developing a body of work in the content areas that is immediately useful to policymakers and practitioners.Progressions could bring focus to research; and instead of undertaking many small disconnected studies, the field could begin to build programs of research addressing the gaps in the progression work. This approach would build a stronger knowledge base for teaching and for the development of instructional tools and supports. The research on progressions could highlight the areas where more research is badly needed (e.g. research on topics lacking progressions, targeting specific age levels where our knowledge is thin, addressing the needs of culturally or linguistically diverse groups who do not perform well in science, etc.).

Learning progressions have enormous potential, but as the recommendations listed above make clear, there is a great deal of work to be done to realize their potential. Still, if we are serious about eliminating achievement gaps and raising the levels of academic achievement in the United States, we must abandon the search for panaceas and quick fixes that has dominated contemporary discussions of school reform and engage in a serious research and development effort to provide our teachers with the tools they need to do the job.Investing in learning progressions would not solve all of our problems, but it would put us on the right path toward finding solutions. 


\section{References}

American Association for the Advancement of Science, Project 2061. (1993). Benchmarks for Science Literacy. New York: Oxford University Press.

Alonzo, A. C., \& Steedle, J. T. (in press). Developing and assessing a force and motion learning progression. Science Education.

Bell, B., Osborne, R., \& Tasker, R. (1985). Appendix A: Finding out what children think. In R. Osborne \& P. Freyberg (Eds.), Learning in science: The implications of children's science (pp. 151-165). Auckland, New Zealand: Heinemann.

Black, P., \& William, D. (1998). Assessment and Classroom Learning. Assessment in Education, 5(1), 7-74.

Briggs, D. C., Alonzo, A. C., Schwab, C., \& Wilson, M. (2006). Diagnostic assessment with ordered multiple-choice items. Educational Assessment, 11, 33-63.

Catley, K., Lehrer, R., \& Reiser, B. (2005). Tracing a proposed learning progression for developing understanding of evolution. Paper commissioned for the Committee on Test Design for K-12 Science Achievement. Center for Education, National Research Council.

Clement, J. (2000). Analysis of clinical interviews: Foundations and model viability. In R. Lesh, and A. Kelly, Handbook of Research Methodologies for Science and Mathematics Education (pp. 341-385). Hillsdale, NJ: Lawrence Erlbaum Associates.

Ericsson, K.A., \& Simon, H. A. (1993). Protocol analysis: Verbal reports as data. Cambridge, MA: MIT Press.

Ginsberg, H.P. (2009). The challenge of formative assessment in mathematics education: children's minds, teachers Minds'. Human Development, 52,109-128.

Gonzales, P., Williams, T., Jocelyn, L., Roey, S., Kastberg, D., \& Brenwald, S. (2008). Highlights from TIMSS 2007: Mathematics and science achievement of U.S. fourth-and eighth-grade students in an international context (NCES 2009-001). Washington, DC: National Center for Education Statistics. Institute of Education Sciences, U.S. Department of Education.

Heritage, M. (2008). Learning progressions: Supporting instruction and formative assessments. Paper prepared for the Formative Assessment for Teachers and Students Collaborative on Assessment for State Standards of the Council of Chief State School Officers.

Kennedy, C.A., \& Wilson, M. ( 2007). Using progress variables to interpret student achievement and progress. BEAR Report Series, 2006-12-01.University of California, Berkeley. 
Krajcik, J., McNeill, K. L., \& Reiser, B. (2008). Learning-Goals-Driven Design Model: Developing Curriculum Materials that Align with National Standards and Incorporate Project-Based Pedagogy. Science Education, 92(1), 1-32.

Kuhn, D. (2005). Education for thinking. Harvard University Press.

Lehrer, R. \& Schauble, L. (2000). Modeling in mathematics and science. In R. Glaser (Ed.), Advances in instructional psychology: Education design and cognitive science (vol. 5, pp. 101-169). Mahway, NJ: Lawrence Erlbaum Associates.

Mohan, L., Chen, J., \& Anderson, C.W. (2009). Developing a K-12 learning progression for carbon cycling in socio-ecological systems. Retrieved from:

http://edr1.educ.msu.edu/EnvironmentalLit/publicsite/html/carbon.html.

National Center for Education Statistics (2006). The Nation's Report Card, Science, 2005: Assessment of Student Performance in Grades 4, 8 and 12 (NCES 2006-466). Washington, DC: Institute of Education Sciences, U.S. Department of Education,.

National Research Council (1996). National science education standards. Washington DC: National Academies Press.

National Research Council (2000). How People Learn: Brain, Mind, Experience and School. Committee on Developments in the Science of Learning. J. D. Bransford, A.L. Brown, \& R.R. Cocking (Eds.). Washington, DC: The National Academies Press.

National Research Council (2001). Knowing what students know: The science and design of educational assessment. Washington, DC: The National Academies Press.

National Research Council (2005). Systems for state science assessments. Committee on Test Design for K-12 Science Achievement. M.R. Wilson, \& M.W. Bertenthal (Eds.). Washington DC: The National Academies Press.

National Research Council (2007). Taking science to school: Learning and teaching science in grades K-8. Committee on Science Learning, Kindergarten through eighth grade.

R.A. Duschl, H.A. Schweingruber, \& A.W. Shouse (Eds.). Washington DC: The National Academies Press.

Organization for Economic Co-operation and Development (OECD) (2007). PISA 2006 science competencies for tomorrow's world (2007). Paris: OECD.

Piaget, J. (1976). The child's conception of the world (J. Tomlinson and A. Tomlinson, transl.). Totowa: Littlefield, Adams \& Co.

Pottenger, F., \& Young, D. (1992). The local environment: FAST 1 foundations in approaches to science teaching. University of Hawaii at Manoa: Curriculum Research and Development Group.

Roberts, L., Wilson, M., \& Draney, K. (1997, June). The SEPUP assessment system: An overview. BEAR Report Series, SA-97-1. University of California, Berkeley.

Salzman, H. \& Lowell, L. (2008). Making the grade. Nature. 453, 28-30.

Schmidt, W., Houang, R., \& Cogan, L. (2002, Summer). A coherent curriculum: A case of mathematics. American Educator, 26 (2):10-26. 
Smith, M. \& O'Day, J. (1991). Systemic school reform. In S. Fuhrman \& B. Malen, (Eds.) The Politics of Curriculum and Testing, (pp. 233-267) Bristol, PA: The Falmer Press.

Smith, C., Wiser, M., Anderson, C.W, Krajcik, J., \& Coppola, B. (2004, October). Implications for children's learning for assessment: Matter and atomic molecular theory. Paper Commissioned for the Committee on Test Design for K-12 Science Achievement. Center for Education, National Research Council.

Smith, C., Wiser, M., Anderson, C.W, \& Krajcik, J. (2006). Implications of research on children's learning for standards and assessment: A proposed learning progression for matter and the atomic molecular theory. Measurement: Interdisciplinary Research and Perspectives, 14(1\&2), 1-98.

Stevens, S.Y., Delgado, C., \& Krajcik, J.S. (2009). Developing a hypothetical multidimensional learning progression for the nature of matter. (In Press).

Valverde, G.A., \& Schmidt. W.H. (1997). Refocusing U.S. math and science education. Issues in Science and Technology, 14(2), 60-66.

Wilson, M. (2005). Constructing measures: An item response modeling approach. Mahwah, NJ: Erlbaum.

Wilson, M. (2008, March). Measuring progressions. In A. C. Alonzo \& A. W. Gotwals (Chairs), Diverse perspectives on the development, assessment, and validation of learning progressions in science. Symposium conducted at the annual meeting of the American Educational Research Association, New York. Retrieved March 30, 2008 from: http://myweb.uiowa.edu/alonzo/aera2008.html.

Wilson, M., \& Carstensen, C. (2007). Assessment to improve learning in mathematics: The BEAR assessment system. In A. Shoenfeld (Ed.), Assessing Mathematical Proficiency. London: Cambridge University Press.

Wiser, M., Smith, C.L., Asbelle-Clark, J., \& Doubler, S. (2009). Developing and refining learning progression for matter: The inquiry project: Grades 3-5. Paper presented at the Annual Convention of the American Educational Research Association: San Diego, CA. 


\section{Meeting Participants}

Alicia Alonzo, Assistant Professor, University of Iowa

Charles (Andy) Anderson, Professor, Michigan State University

Tom Corcoran, CPRE Co-Director, Teachers College, Columbia University

Karen Draney, Senior Researcher, Berkeley Evaluation \& Assessment Research Center (BEAR).

Ravit Golan Duncan, Assistant Professor, Rutgers University

Janice Earl, National Science Foundation

Amelia Gotwals, Assistant Professor, Michigan State University

Joseph Krajcik, Professor, University of Michigan

Richard Lehrer, Professor, Vanderbilt University

Charles Luey, Director, Science Product Management, Pearson Education

Ron Marx, Dean, College of Education, University of Arizona

Fritz Mosher, Senior Research Consultant for CPRE, Teachers College, Columbia University

Mike Padilla, Emeritus Professor, University of Georgia

James Pellegrino, Professor, University of Illinois-Chicago

Linda Reddy, Supervising Editor, Science Curriculum, Pearson Education

Brian Reiser, Professor, Northwestern University

Ann Rivet, Assistant Professor, Teachers College, Columbia University

Aaron Rogat, Senior Scientist, CPRE, Teachers College, Columbia University

Jo Ellen Roseman, Director, Project 2061, AAAS

Leona Schauble, Professor, Vanderbilt University

Mark Wilson, Professor, University of California-Berkeley, BEAR

Meeting Chair, Joseph Krajcik

Meeting Lead Organizers, Aaron Rogat and Tom Corcoran 

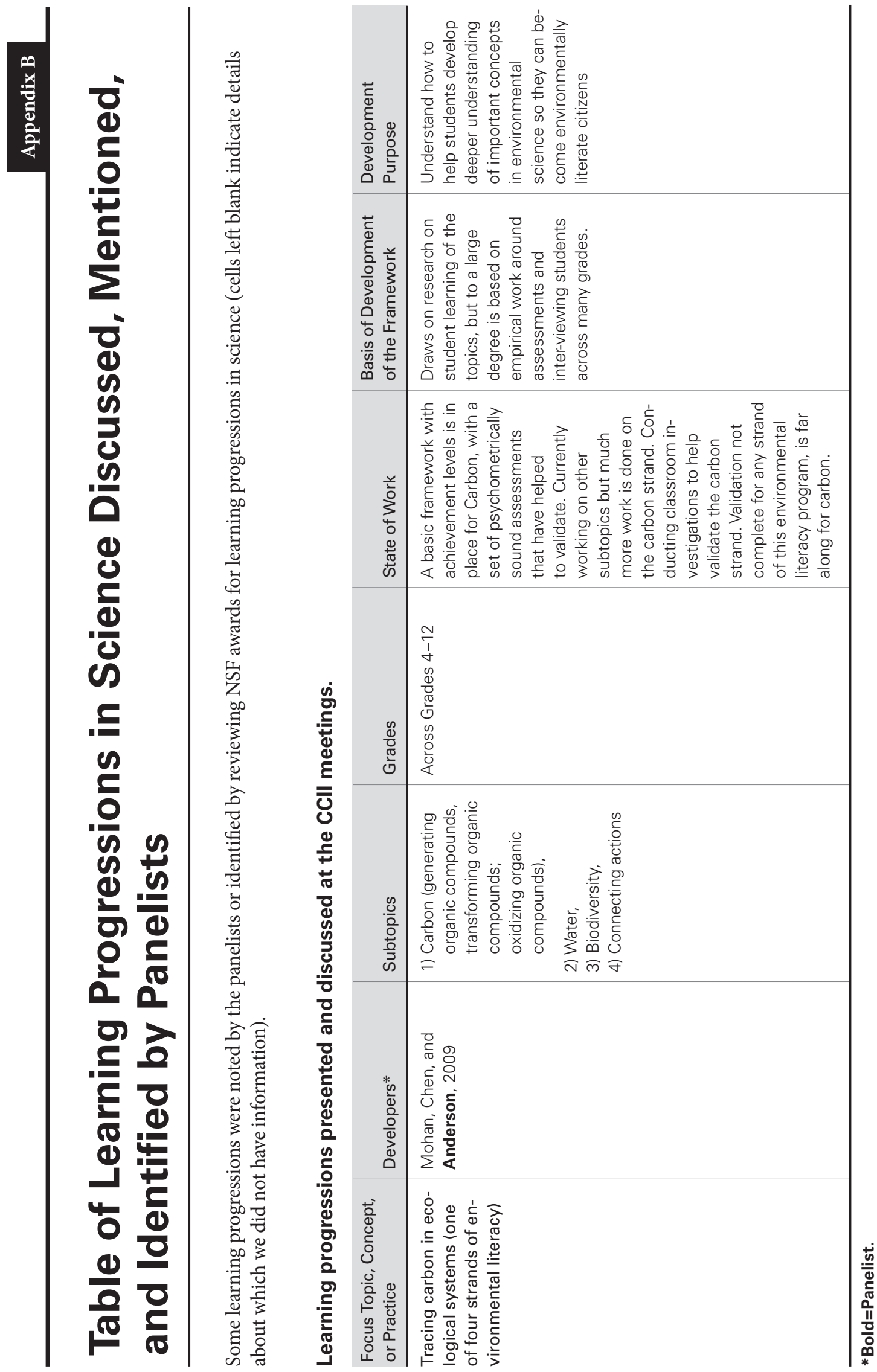


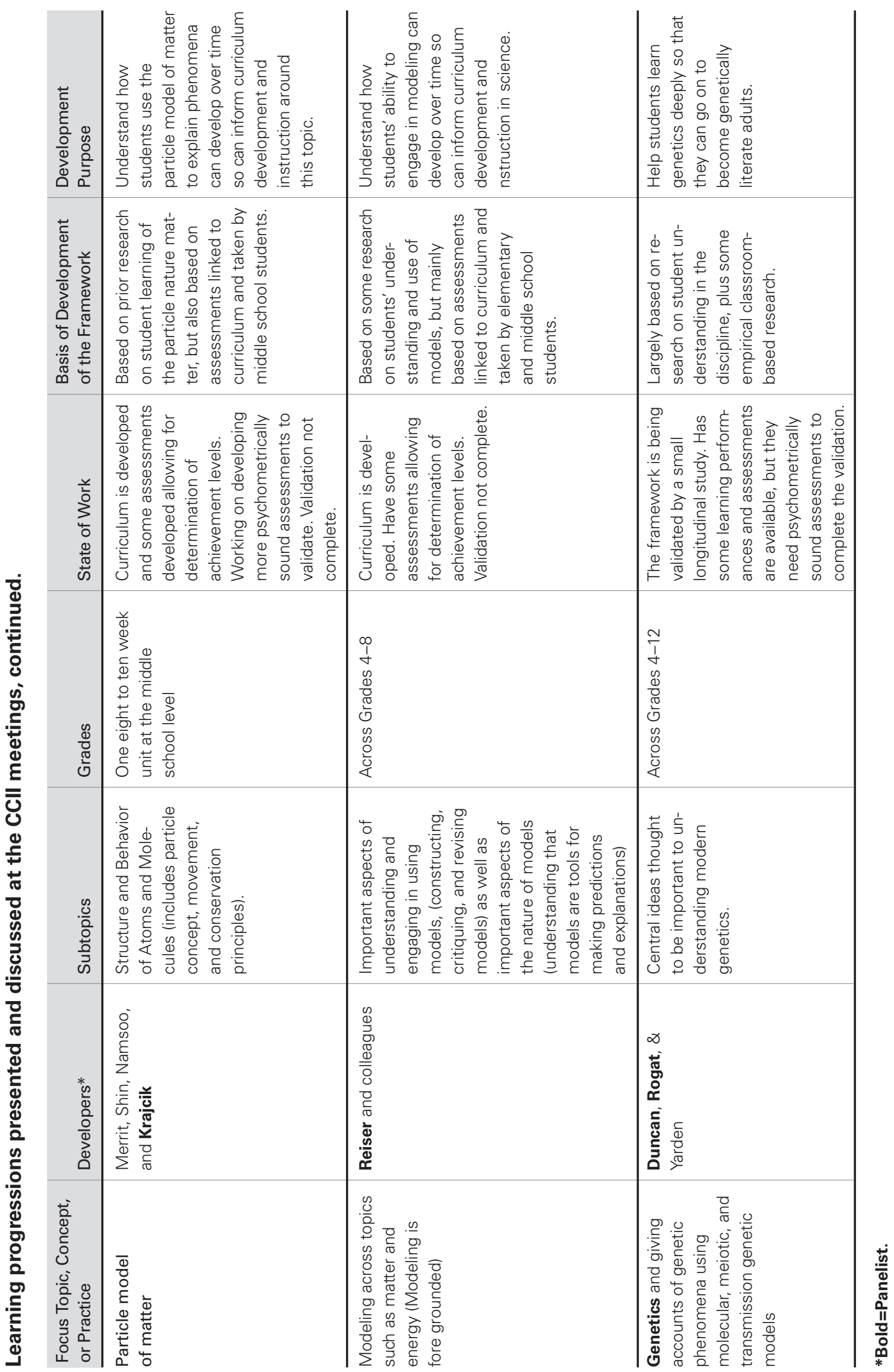




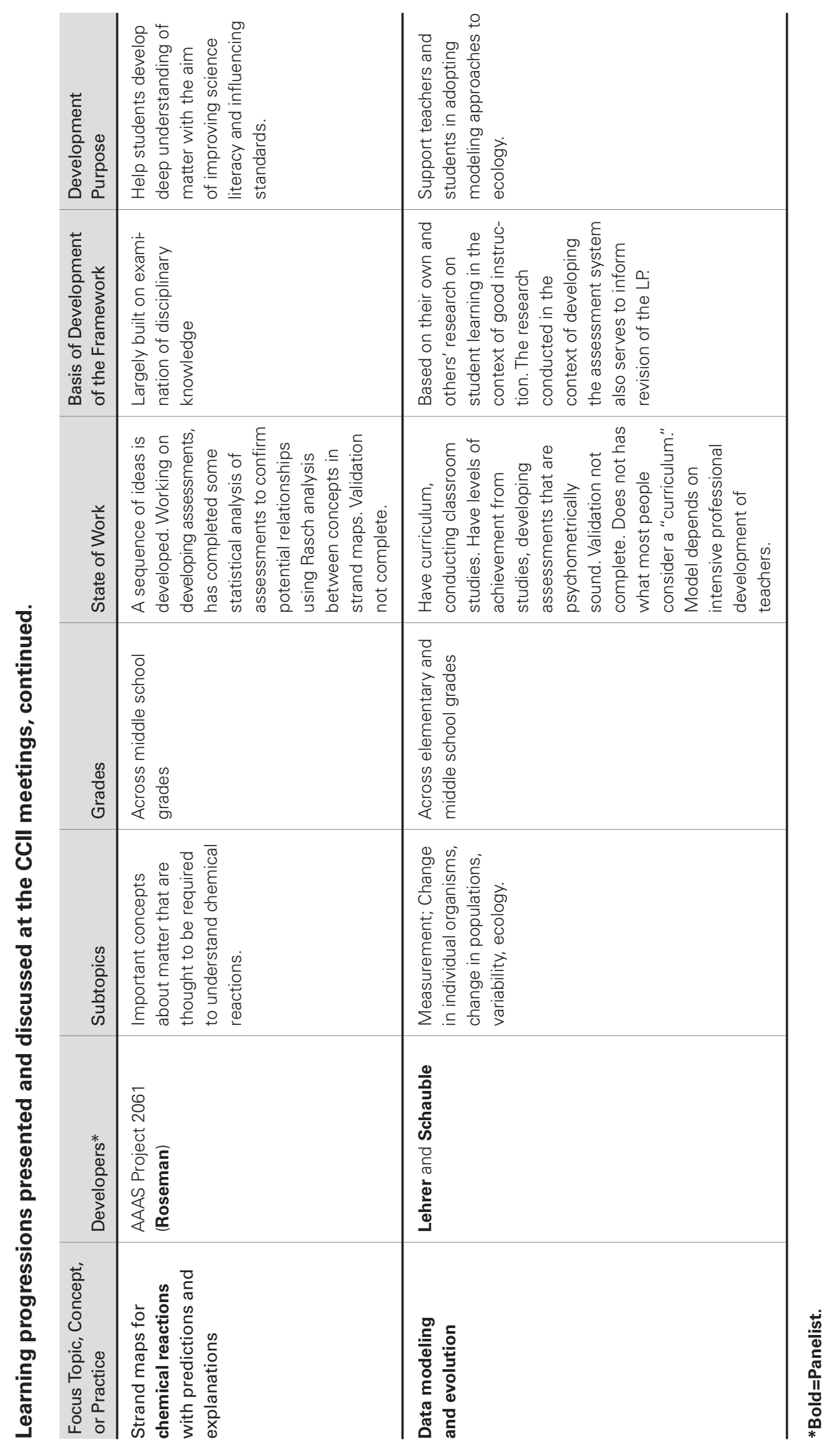




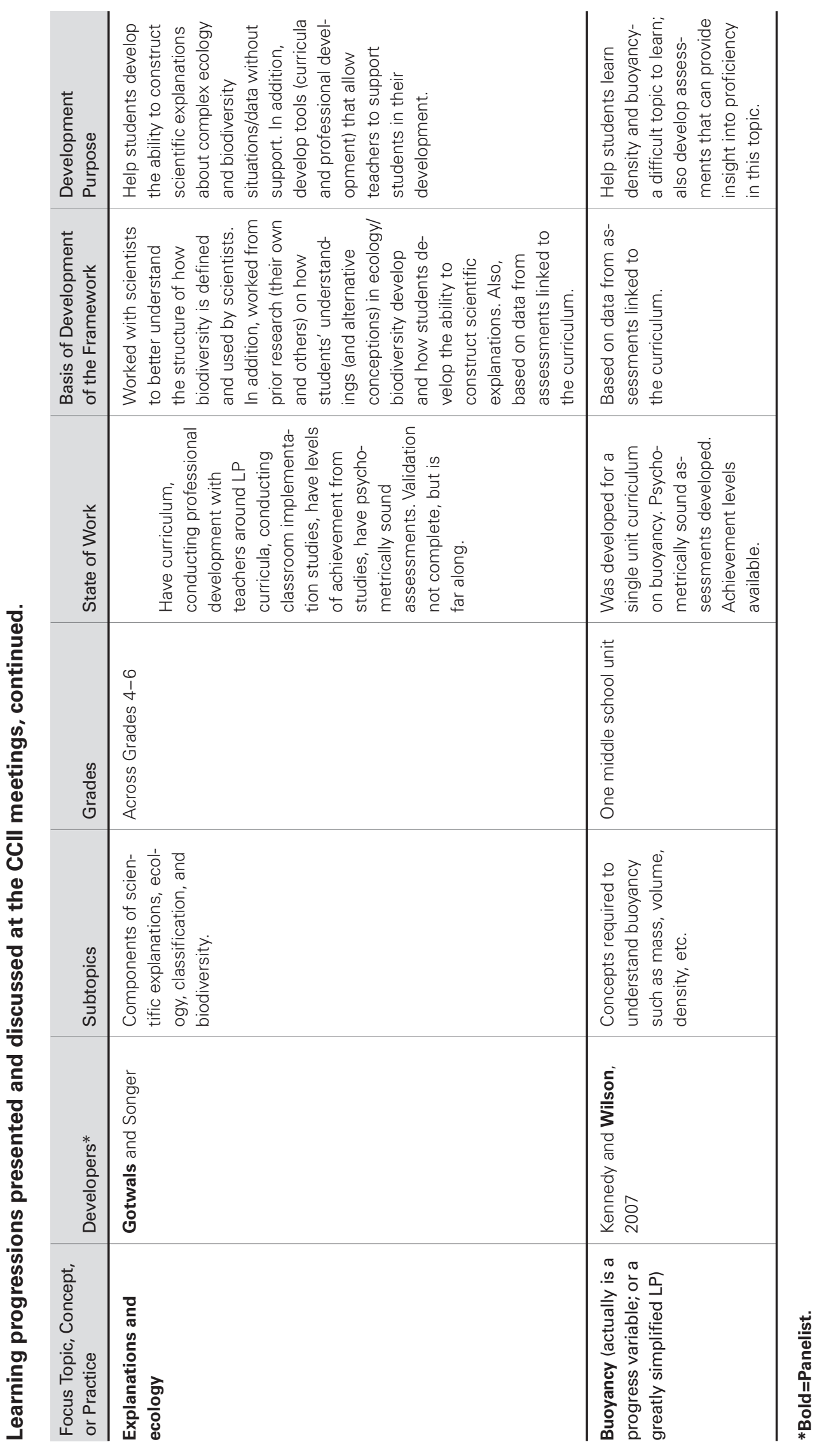




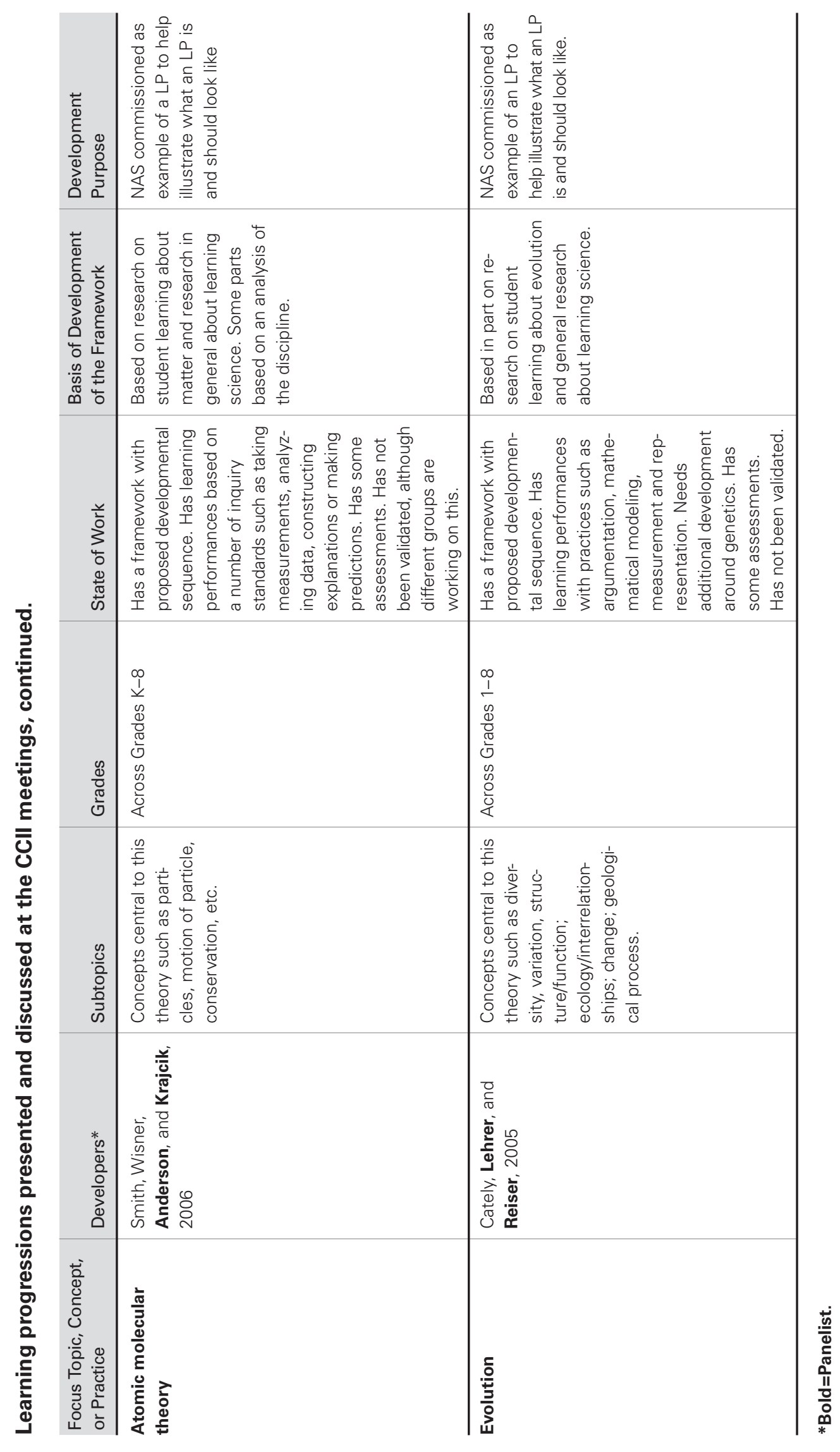


66

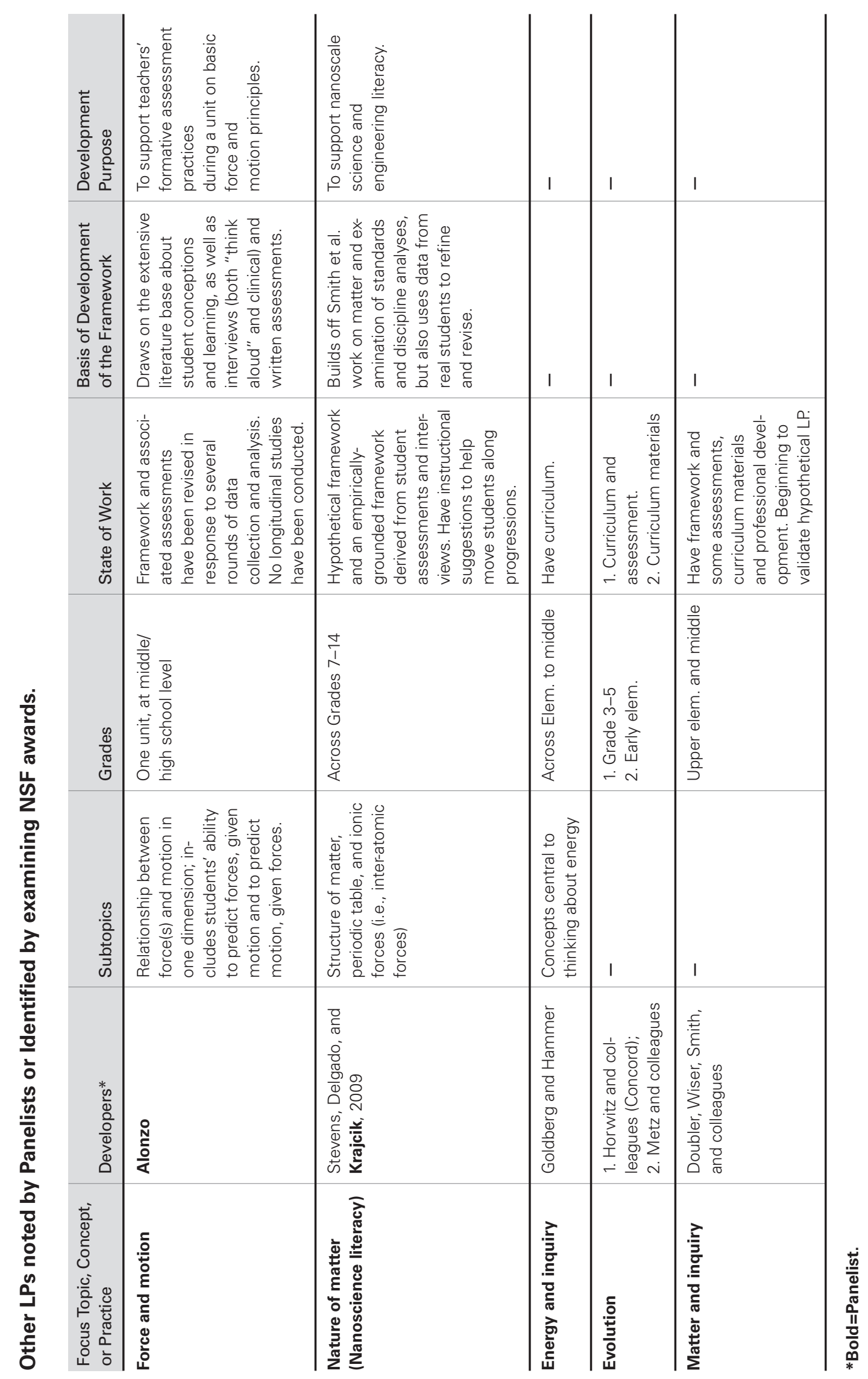




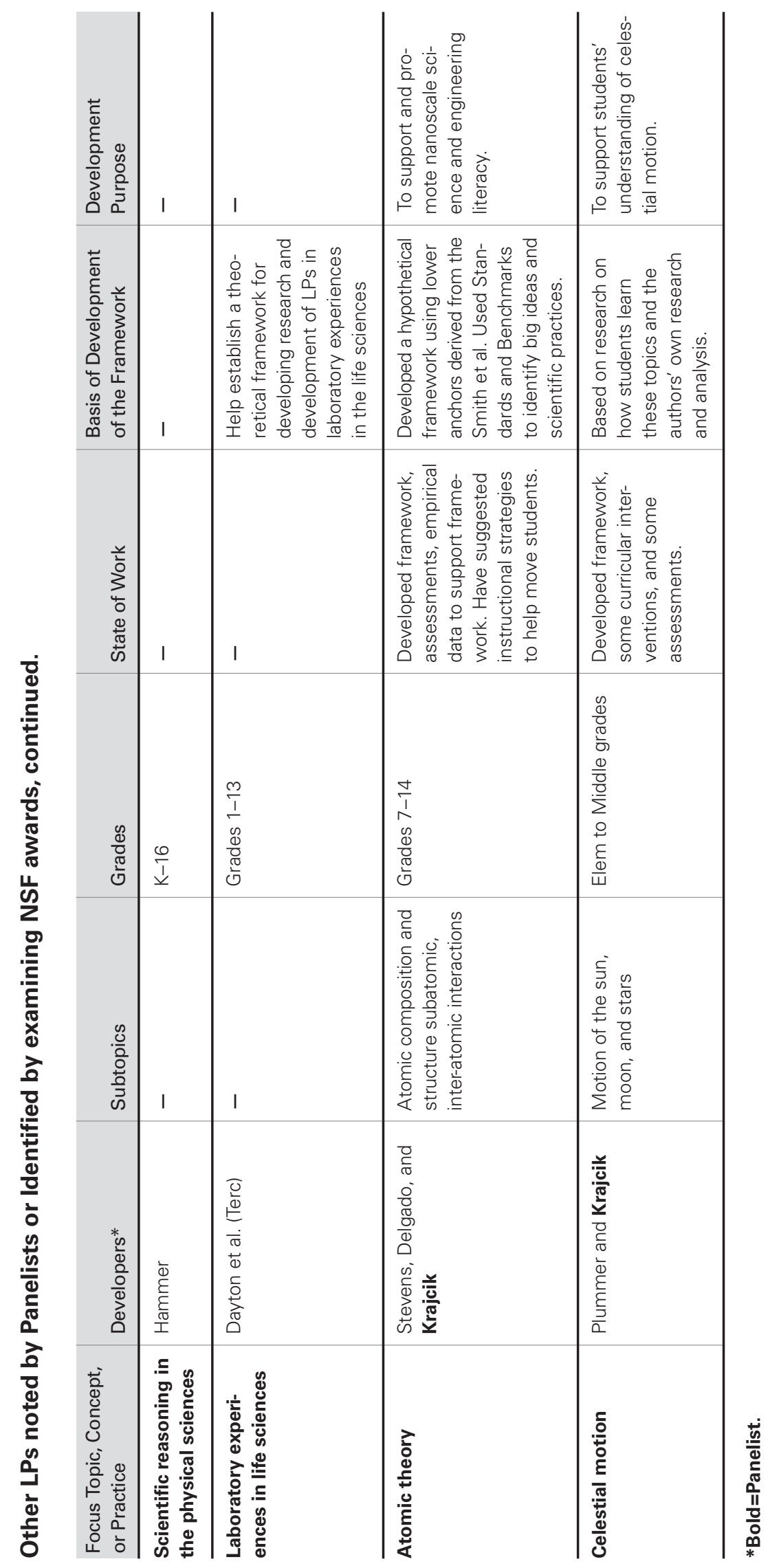




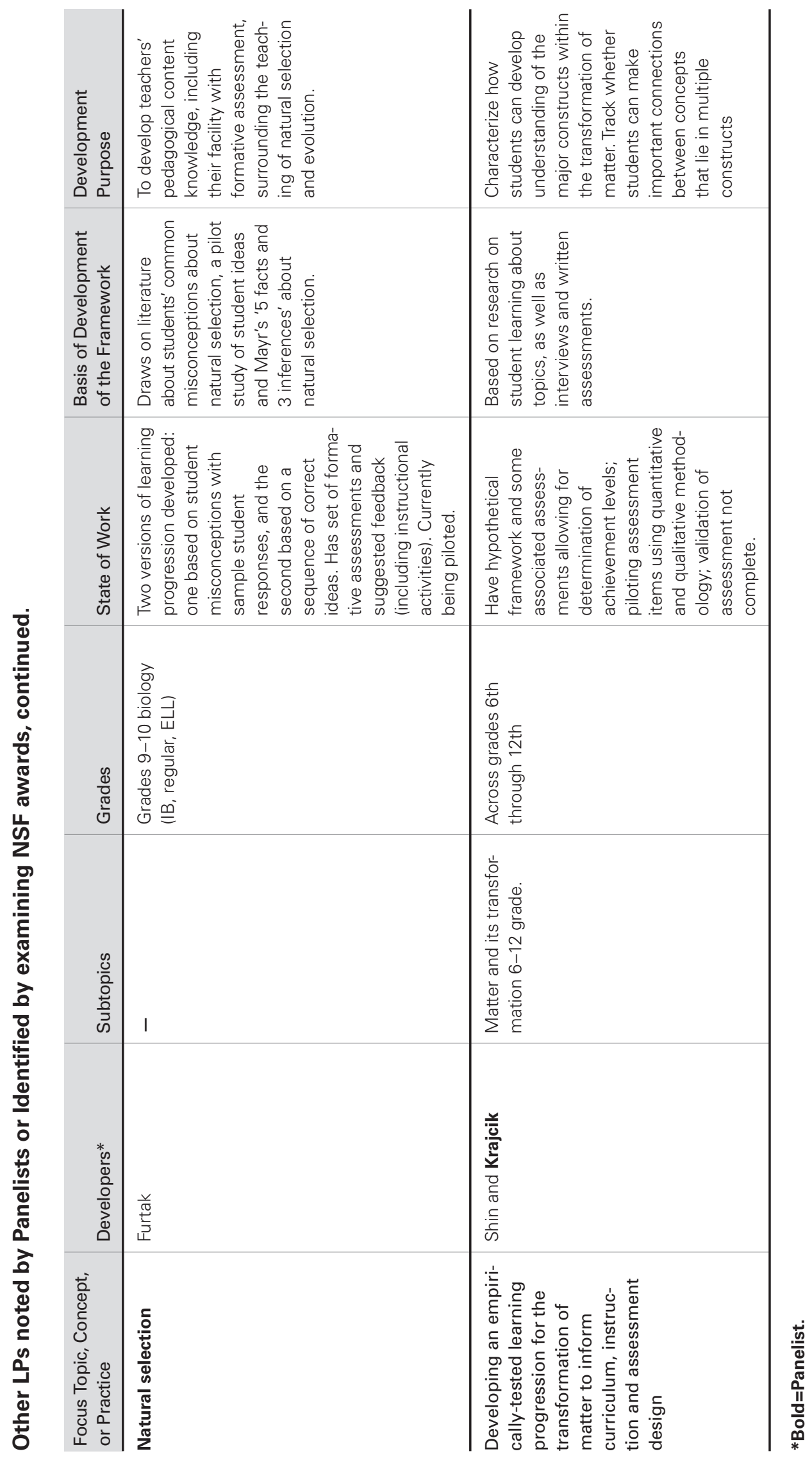




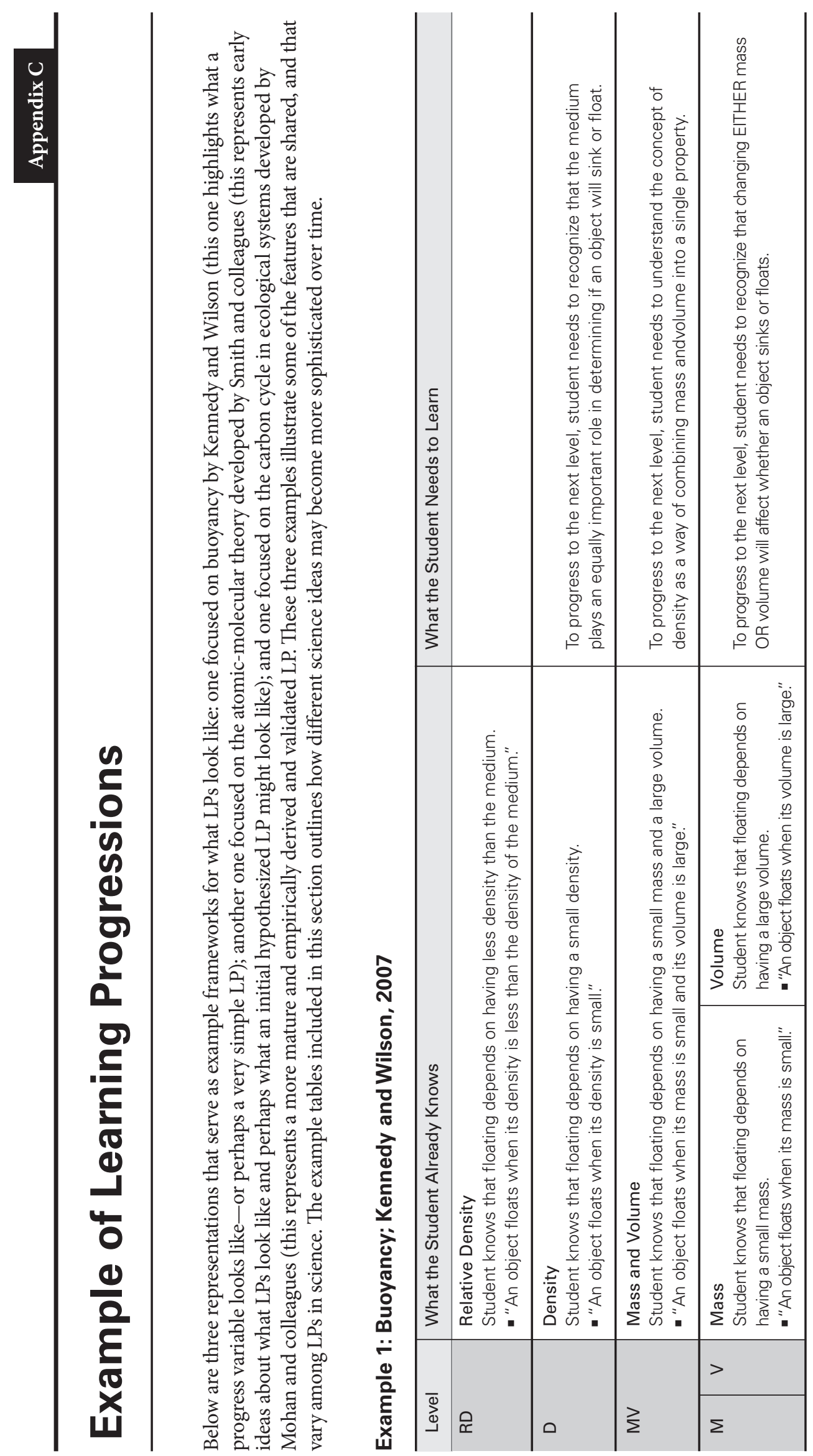

69 


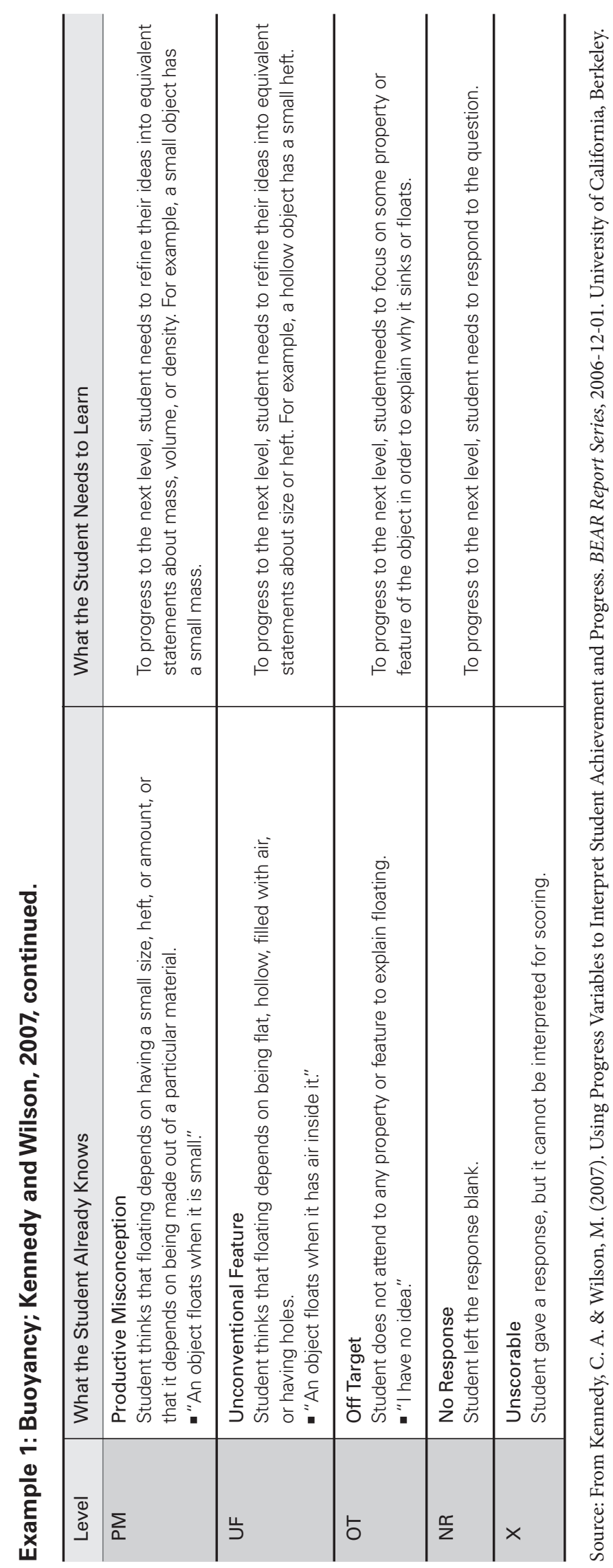




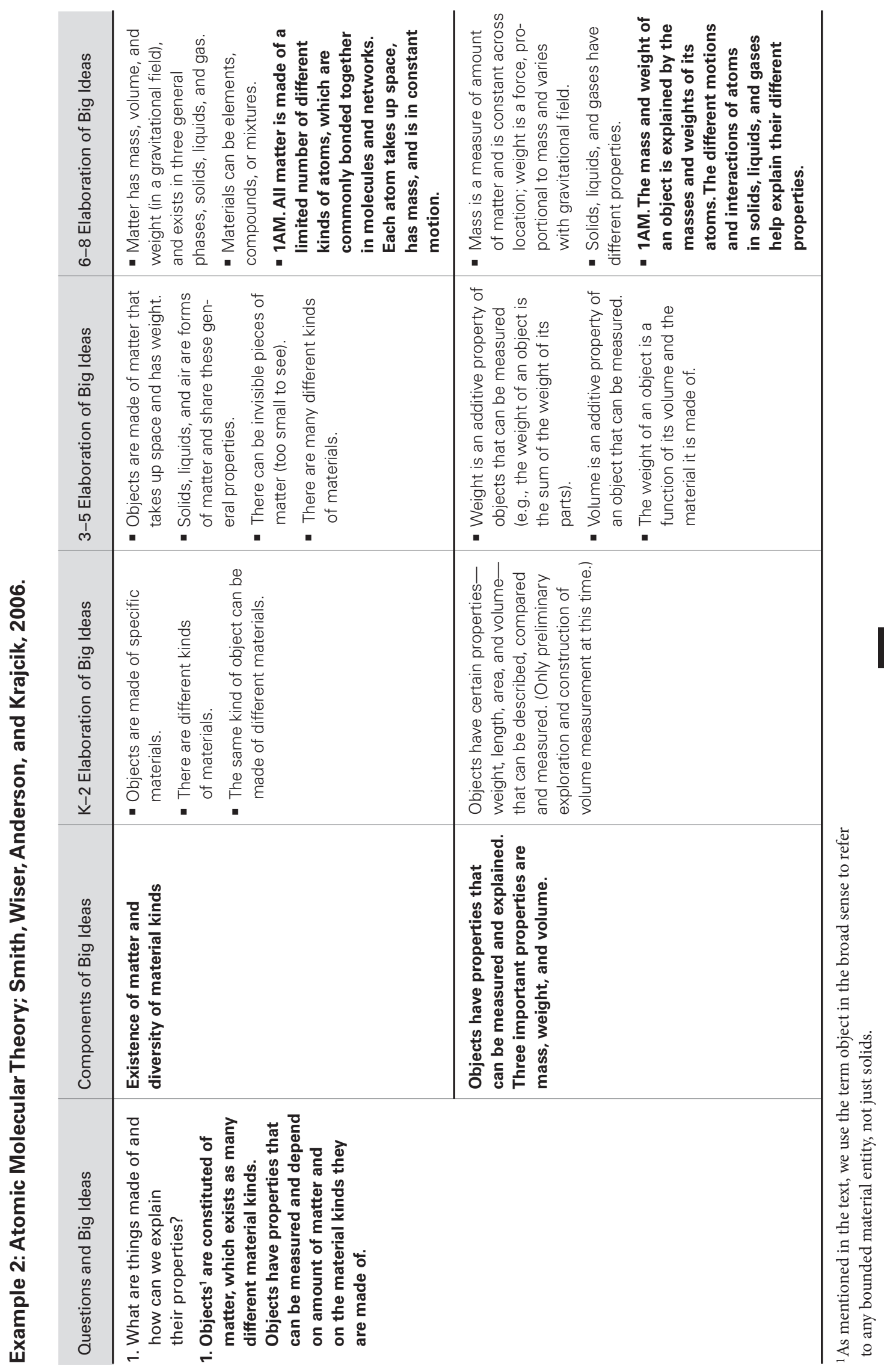




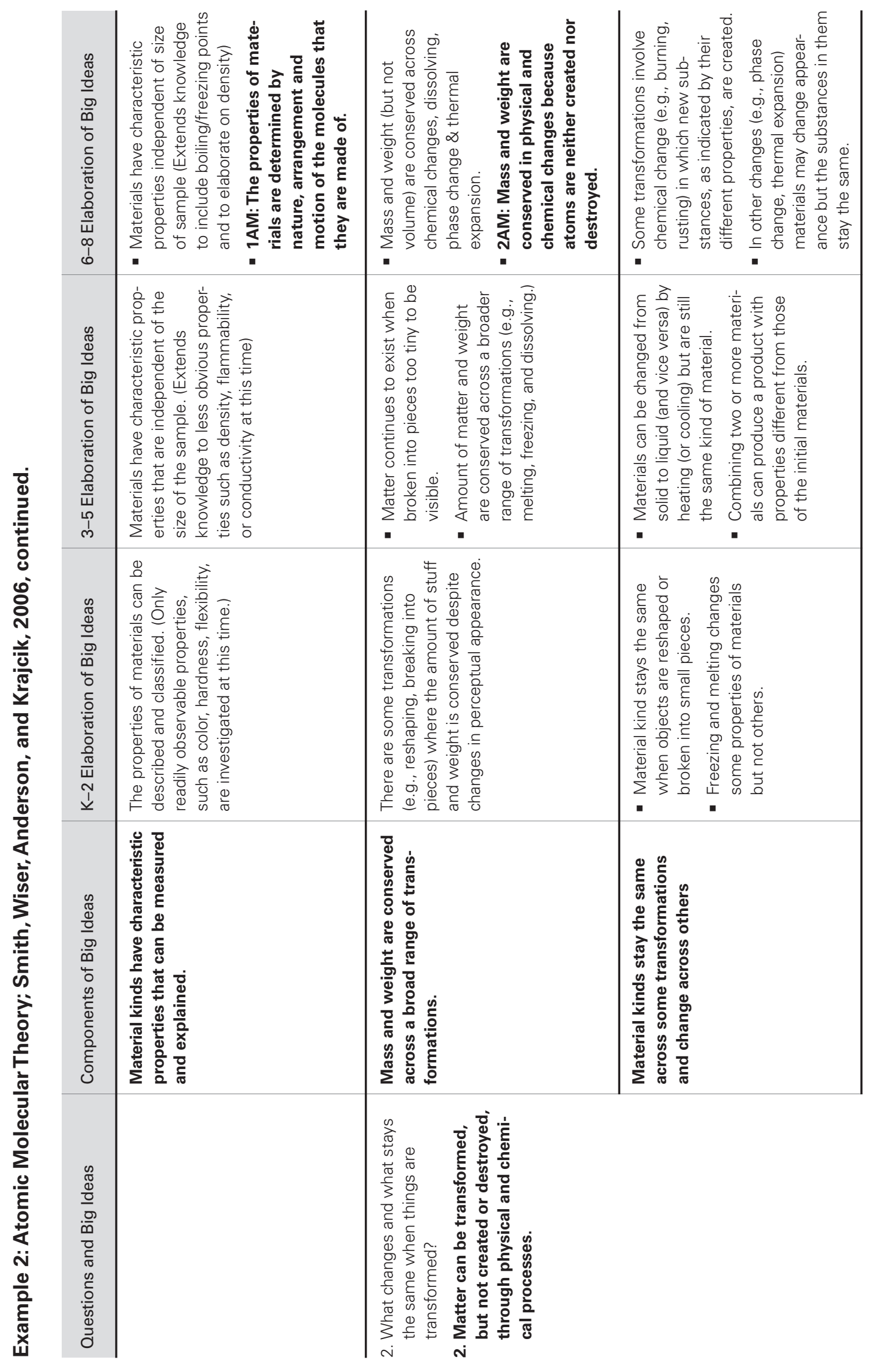




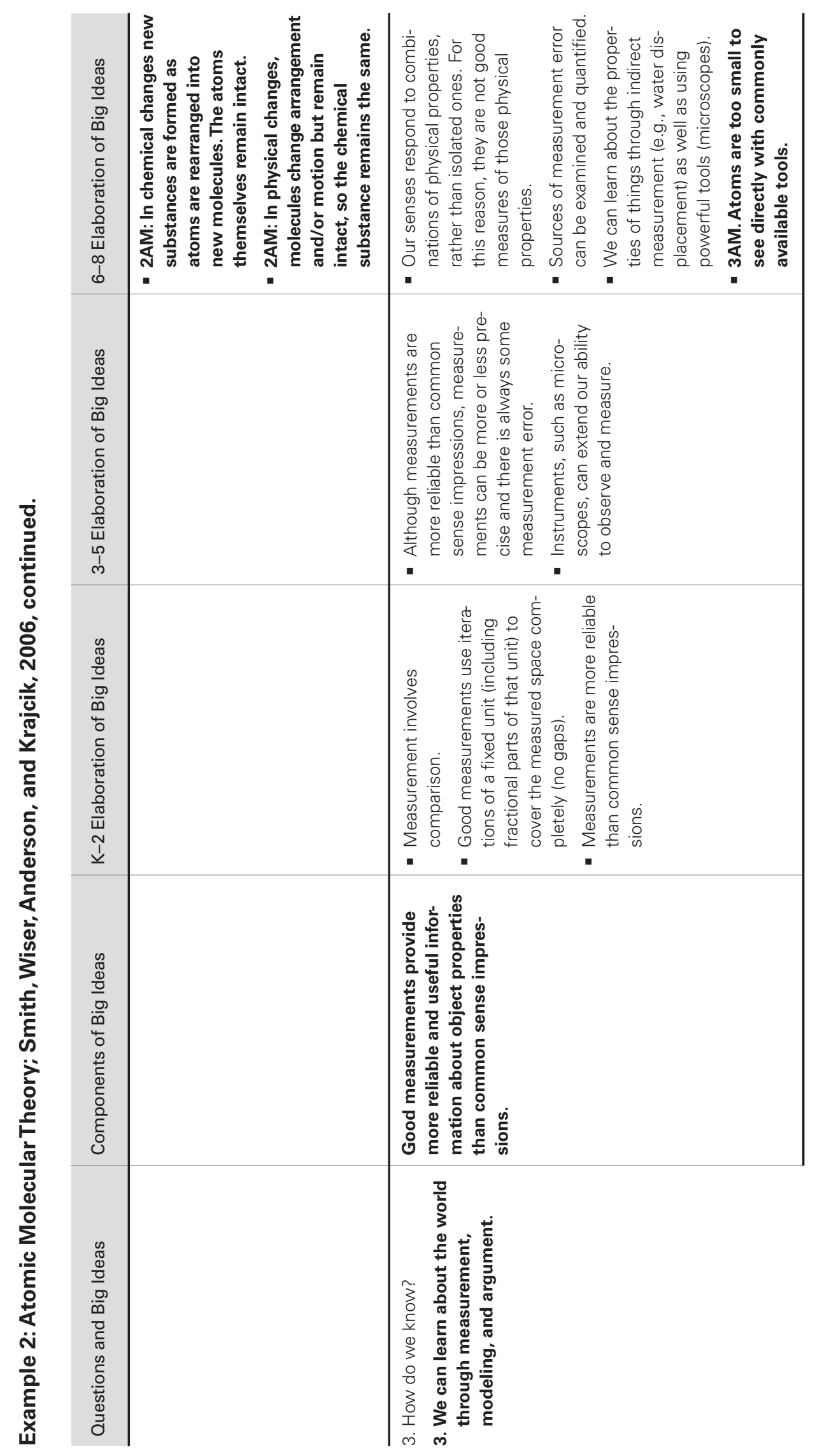




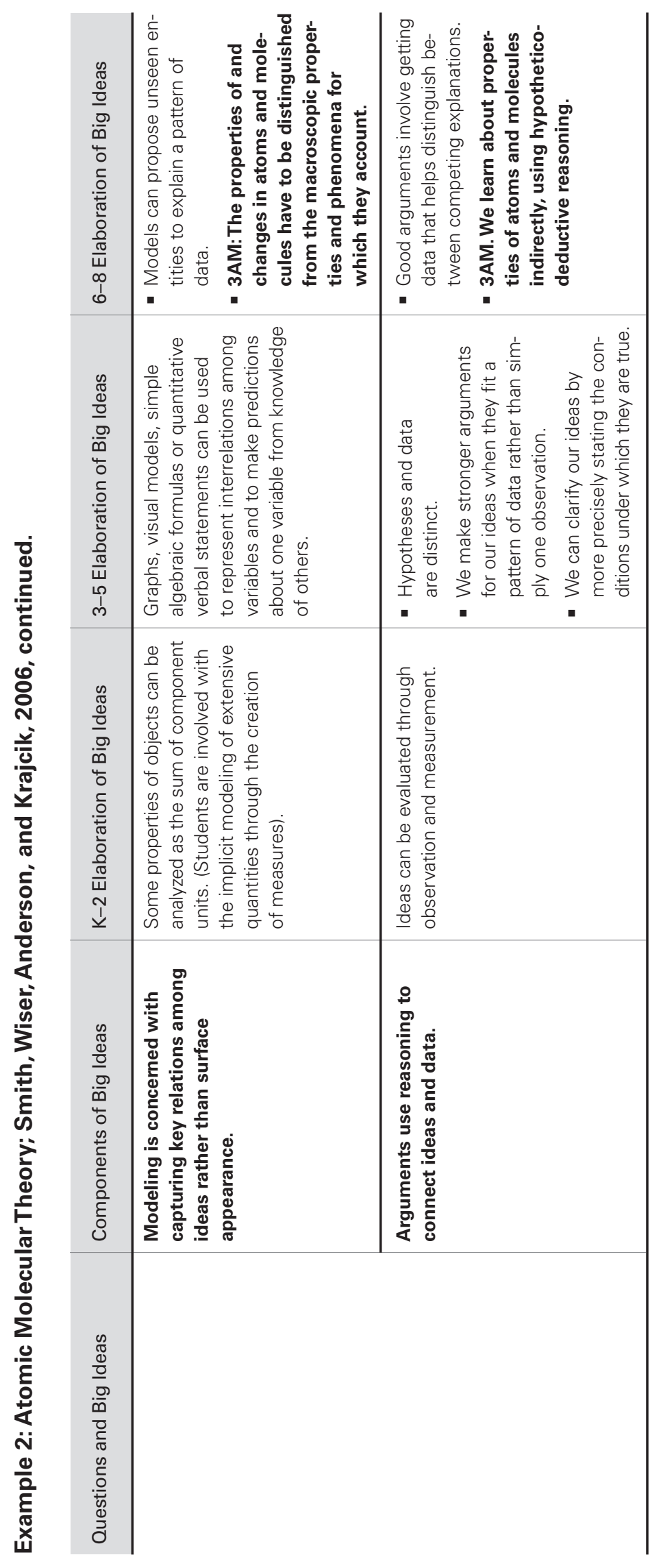




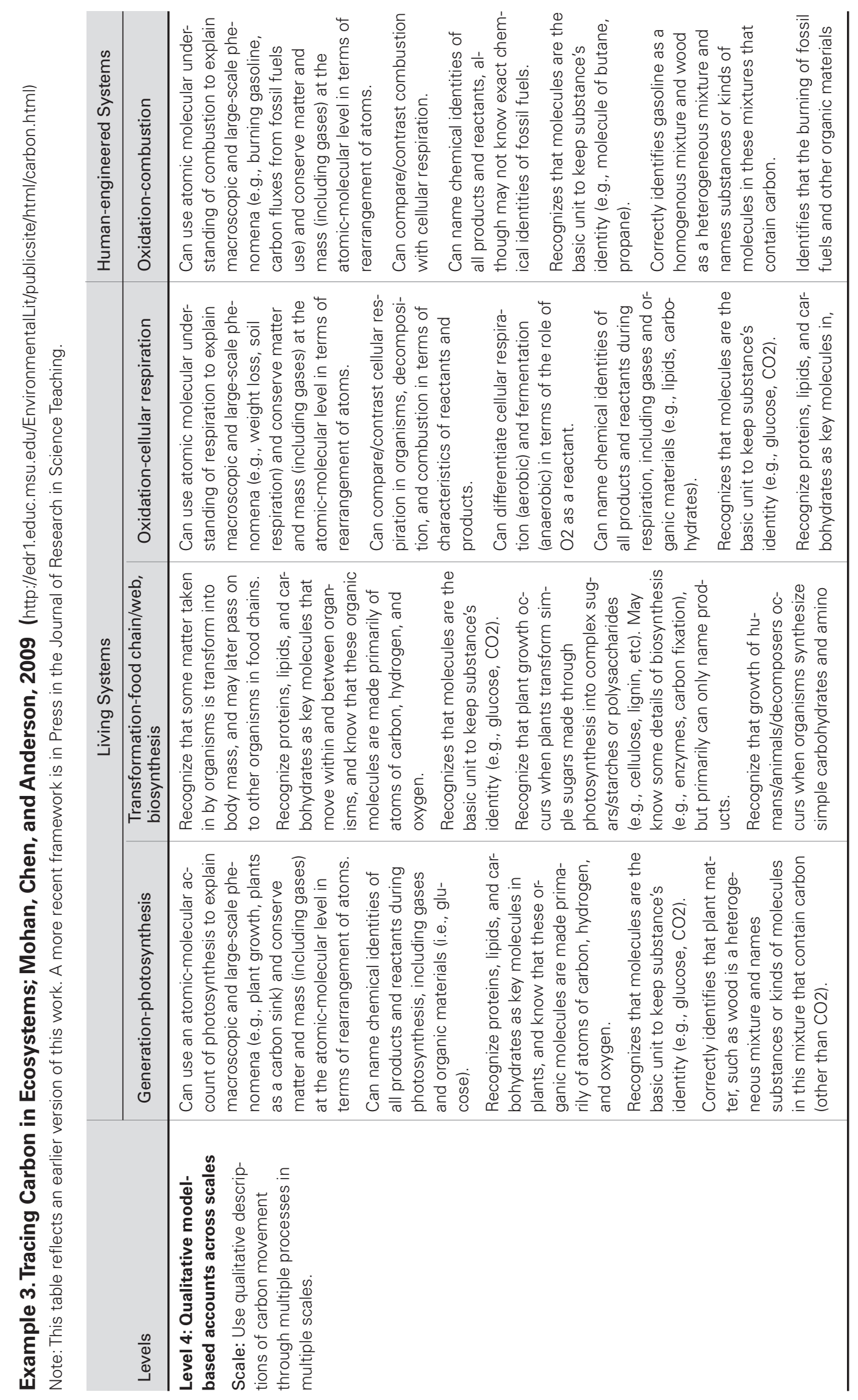




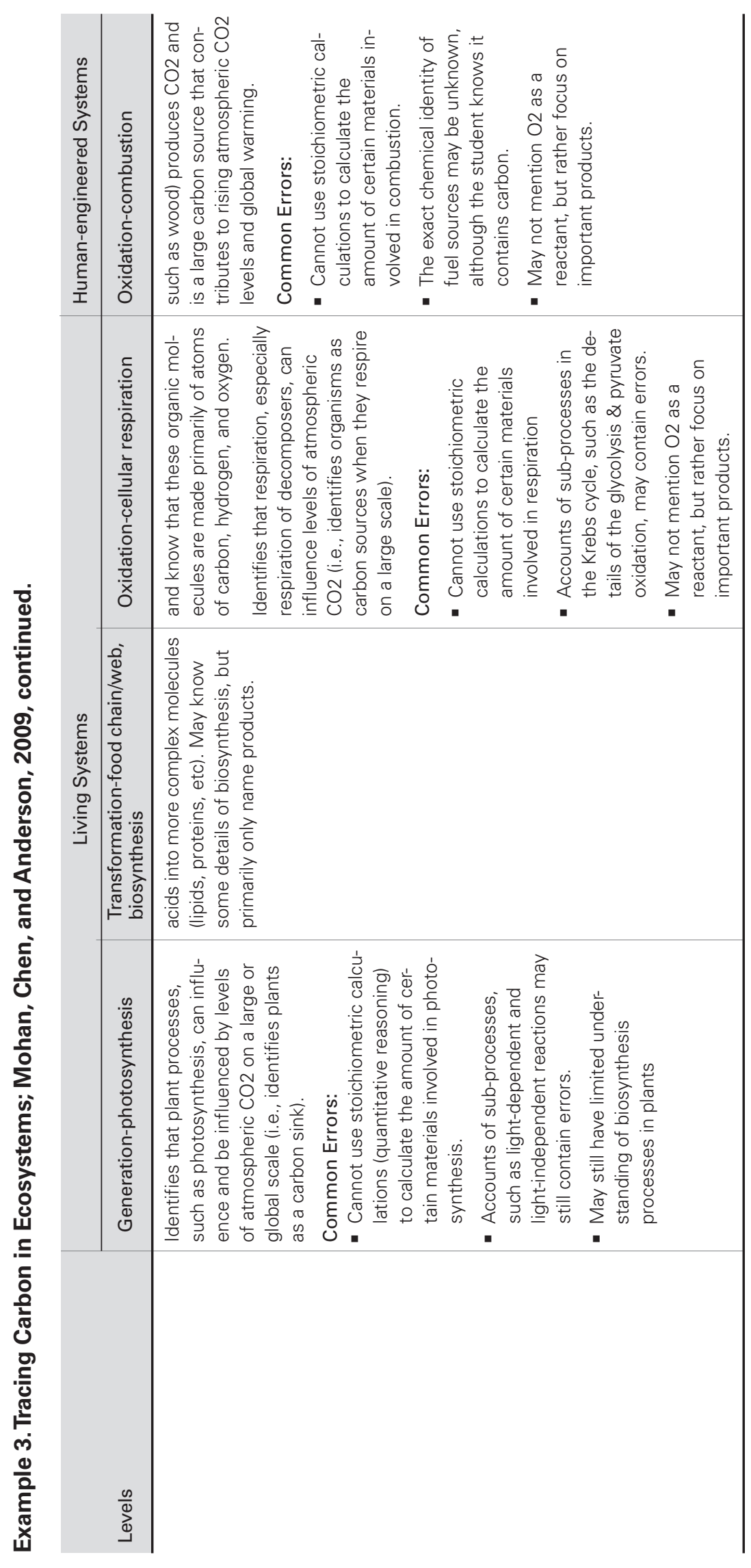




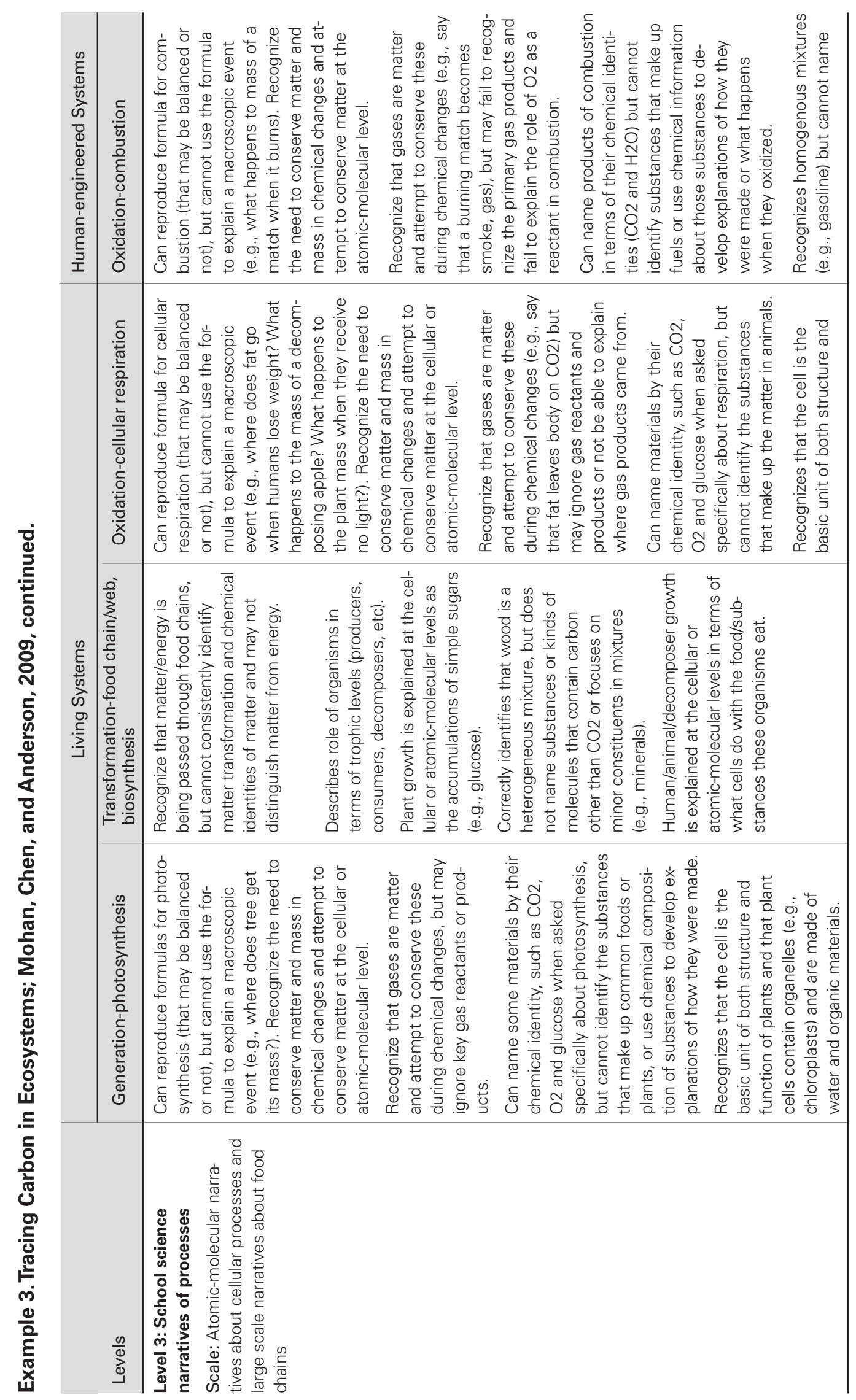




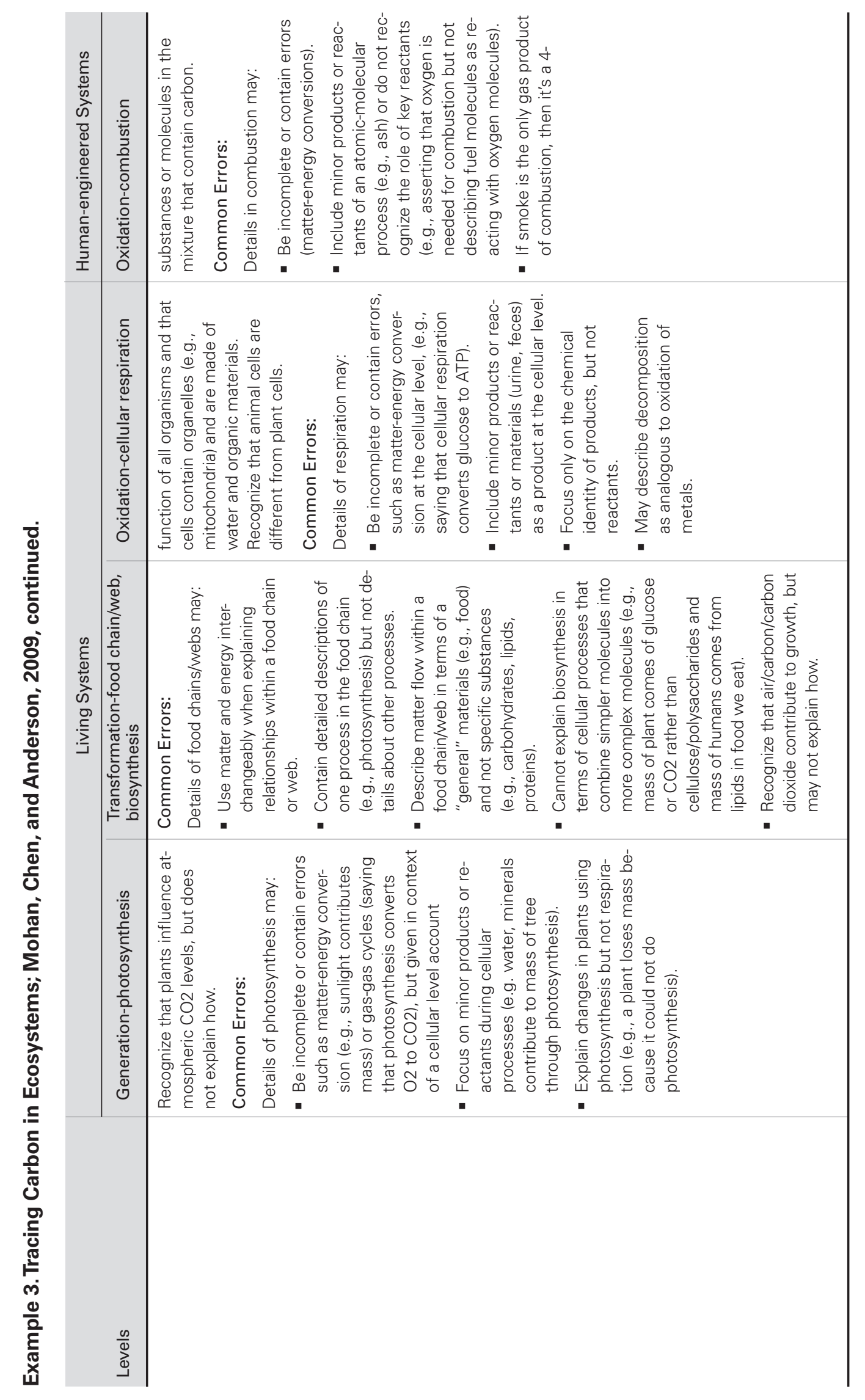




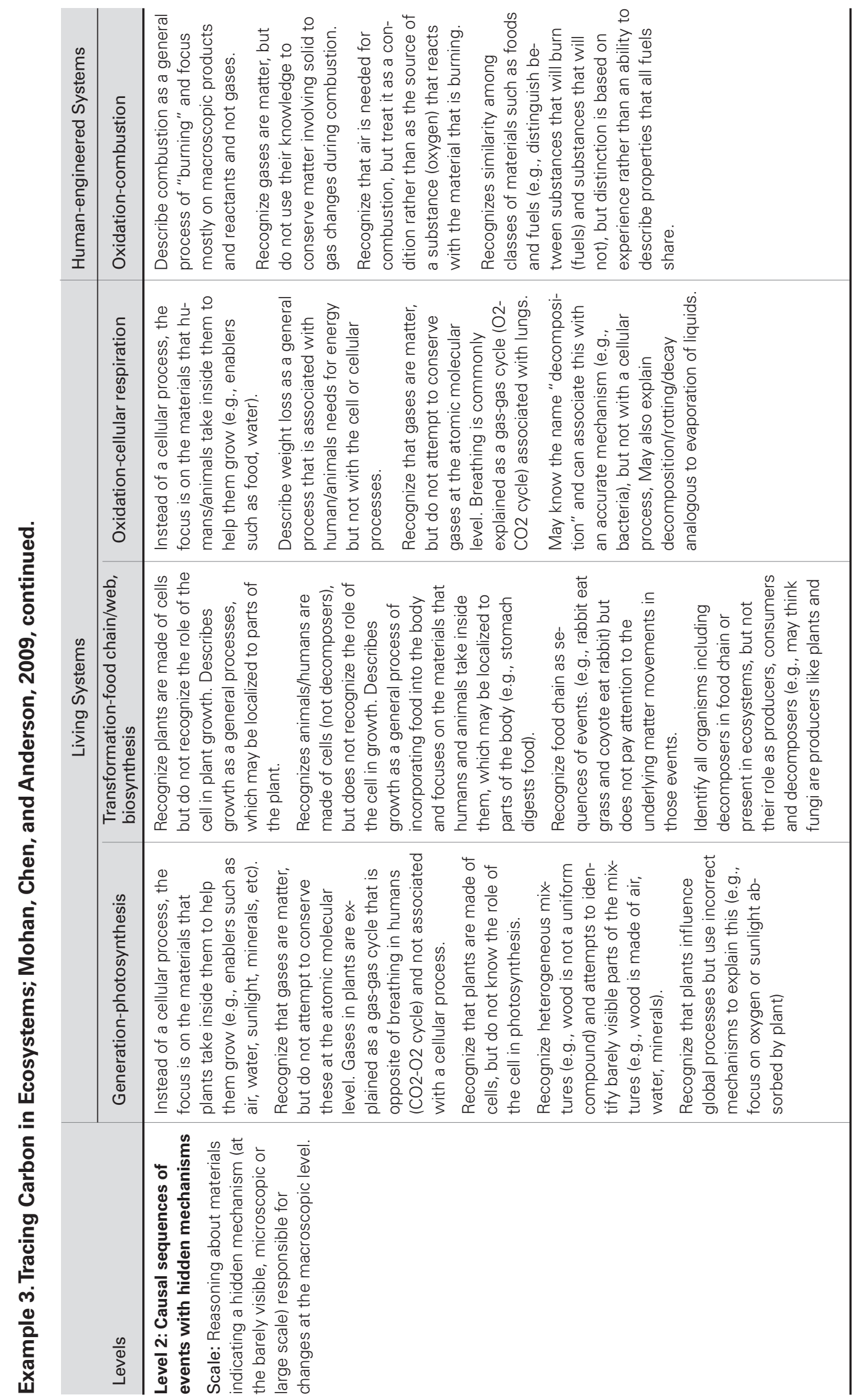




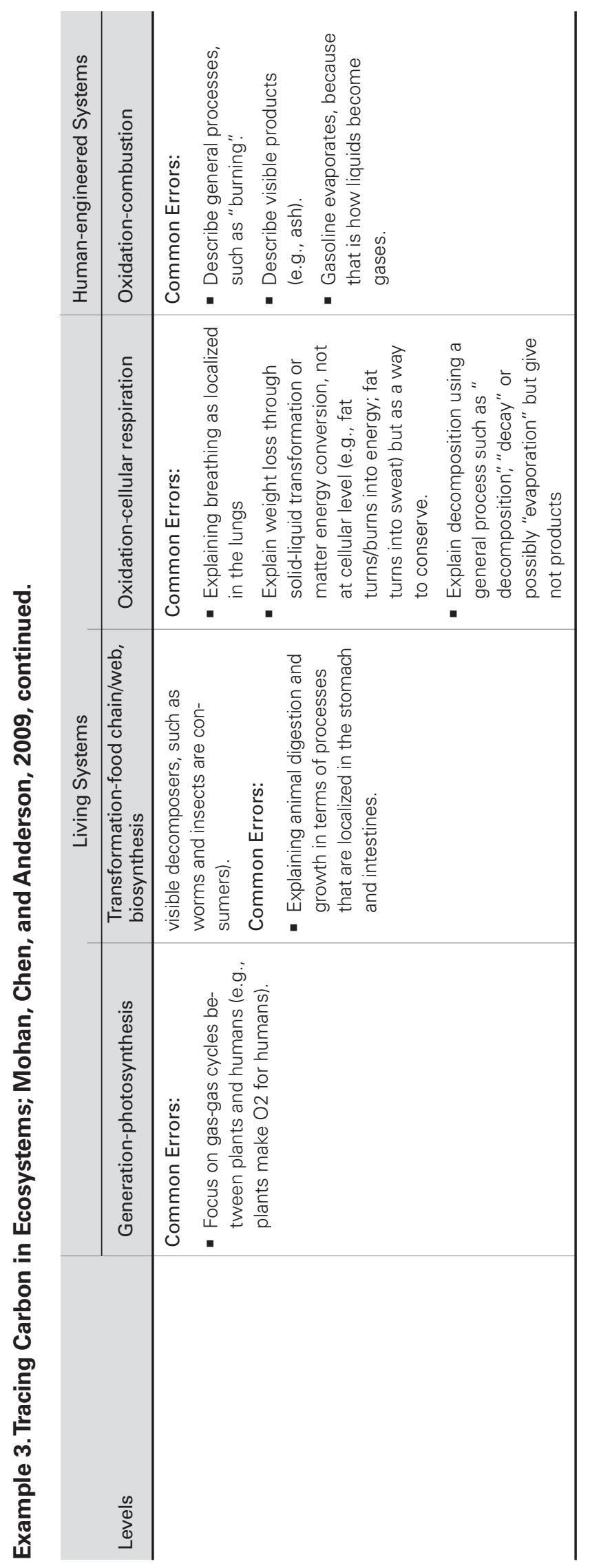




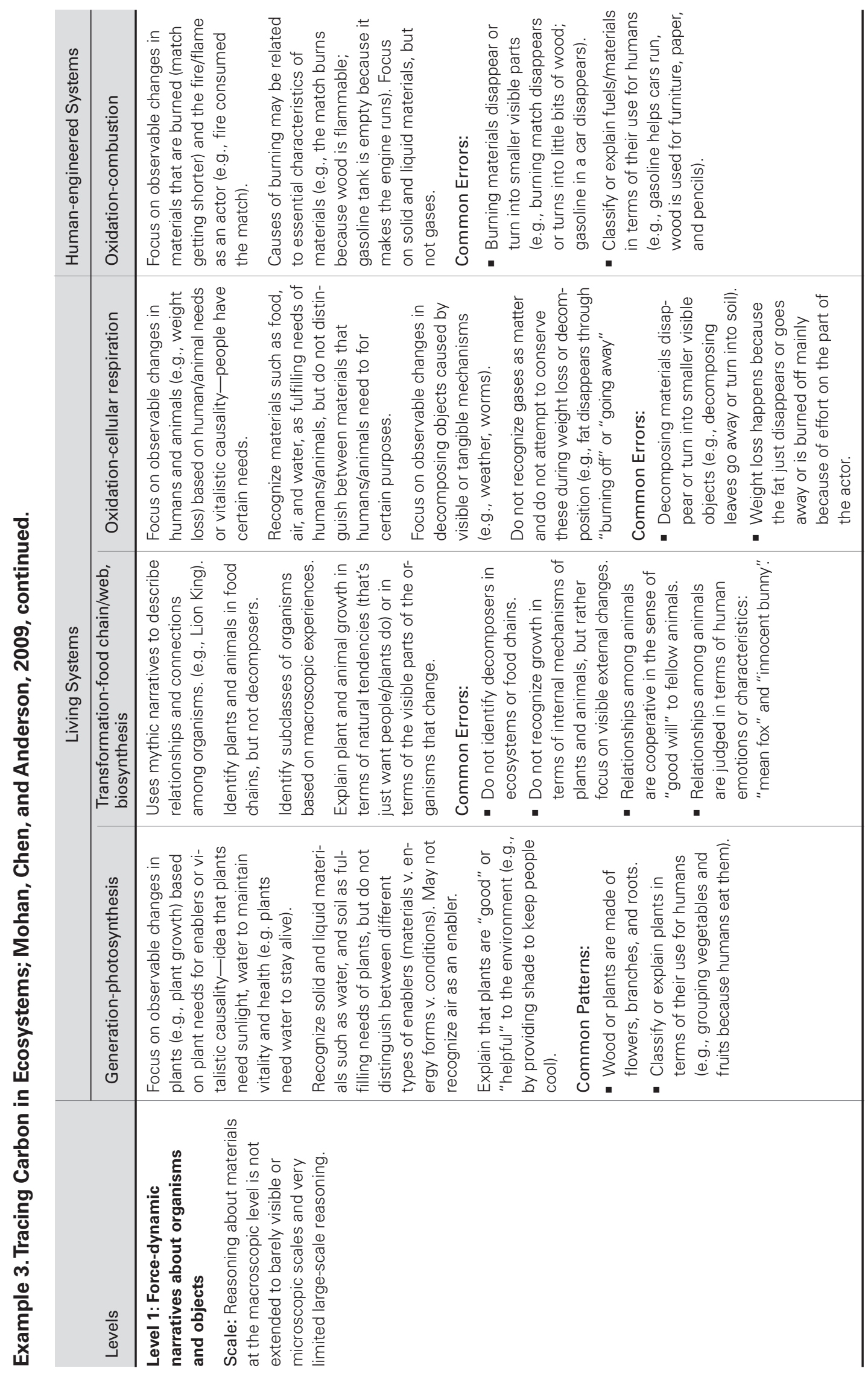

81 


\section{Nondiscrimination Statement}

The University of Pennsylvania values diversity and seeks talented students, faculty, and staff from diverse backgrounds. The University of Pennsylvania does not discriminate on the basis of race, sex, sexual orientation, religion, color, national, or ethnic origin, age, disability, or status as a Vietnam Era Veteran or disabled veteran in the administration of educational policies, programs or activities; admissions policies, scholarships or loan awards; athletic, or University administered programs or employment.

Questions or complaints regarding this policy should be directed to Executive Director, Office of Affirmative Action, 1133 Blockley Hall, Philadelphia, PA 19104-6021 or 215.898.6993 (Voice) or 215.898.7803 (TDD). 


\section{GRE}

Consortium for Policy Research in Education

Copyright 2009 by the Consortium for Policy Research in Education, Philadelphia, PA. 